\title{
ARe All 'Legal Dollars’ Created Equal?
}

\author{
BY
}

\author{
YUVAL FELDMAN \& DORON TEICHMAN*
}

\begin{abstract}
"Whether you like it or whether you do not money is money and that is all there is about it ${ }^{\prime \prime}$
\end{abstract}

\section{INTRODUCTION}

Dollars are fungible. That is one of the basic assumptions of classic economic theory. ${ }^{2}$ The practical meaning of this assumption is that a win of $\$ 300$ in a football bet, a $\$ 3$ increase in the price of a stock for which one owns 100 shares, or a $\$ 300$ rise in the value of a pension will all affect the consumption behavior of the individual in an identical fashion. ${ }^{3}$ Building on this assumption, law and economics scholars have also treated legal payments as fungible. To put things in the terminology often used by legal economists, legal payments are a price set for an activity. Just as a dollar paid for a tomato is identical to a dollar paid for a cucumber, so are a dollar paid as a pollution tax to the government and a dollar paid as compensation to the party injured by the pollution. The two simply represent the price a polluter must pay in order to engage in the polluting activity.

Recently, Gneezy and Rustichini used an experimental setting in order to explore whether fines actually function as prices. ${ }^{4}$ In their study they imposed a monetary fine on parents who were late picking up their child from a day-care center. After the introduction of the fine, they observed a steady increase in the number of parents coming in late. ${ }^{5}$ This result runs contrary to traditional deterrence models that predict that increasing the cost of an activity will necessarily decrease the rate at which it is performed. Gneezy and Rustichini offer two explanations for their surprising results. First, the introduction of the fine may have changed parents' perception of the social dynamic between themselves and the day-care center. That is to say, parents may have viewed the fine as a price for arriving late. According to this logic, as long as they paid the price for such behavior, parents felt comfortable being

\footnotetext{
* Assistant Professor Bar-Ilan University and Assistant Professor the Hebrew University of Jerusalem (Order of Authors is Alphabetical). For helpful comments we thank Tzili Dagan, Ehud Guttel, Miri Gur-Arye, Assaf Hamdani, Daphna Lewinsohn-Zamir, Barak Medina, Koby Nussim, Oren Perez and Jeffrey Rachlinski. For valuable research assistance we thank, Zev Iversen and Tami Shterenhal. Generous support for this study was provided by the Marie Currie research grant MIRG-CT 029168.

${ }^{1}$ Viviana A. Zelizer, The Social Meaning of Money 2 (1994) (quoting Gertude Stein, Money, SATURDAY EVENING POST, July 13 ${ }^{\text {th }}, 1936$ ).

${ }^{2}$ This assumption served as the basis for modern consumption theories according to which individuals smooth their consumption over time according to their permanent income. See generally, MILTON FRIEDMAN, A THEORY OF THE CONSUMPTION FUNCTION (1957).

${ }^{3}$ Richard Thaler, Anomalies: Saving, Fungibility, and Mental Accounts, 4 J. ECON. PERSP. 193, 194 (1990).

${ }^{4}$ Uri Gneezy and Aldo Rustichini, A Fine is a Price, 29 J. LEGAL StUd. 1 (2000).

${ }^{5} \mathrm{Id}$. at $5-8$.
} 
late. ${ }^{6}$ Second, the fine may have revealed information to parents regarding the expected sanction for tardiness. Thus, parents who were previously punctual out of fear of incurring a costly sanction may have exercised less caution after learning the actual cost of the behavior, as revealed by the fine. ${ }^{7}$

While Gneezy and Rustichini offer some interesting insights regarding the relationship between fines and prices, one should note that the fine imposed on parents in their study included two unique characteristics that do not necessarily represent all legal payments. First, the imposition of the fine was certain. All of the parents knew that they would be fined every time they came in late. In most realworld situations, however, fines are imposed probabilistically. A driver speeding on the freeway can end up paying a fine, but can also end up paying nothing. Second, the payment of the fine was made directly to the entity that was harmed by the wrongdoer. Fines, on the other hand, are in many cases paid to third parties that were not directly harmed by the regulated act. Paying an emissions tax provides the government with income, but does not assure any compensation for the people harmed by the pollution.

Our goal in this study is to explore how different characteristics of legal payments affect the way in which people perceive them, and as a result the way they might behave. The three characteristics we focus on are: (a) the timing of the payment - we distinguish between payments that are made prior to committing the harmful act and those made after the act has already been committed; (b) the identity of the party to which the payment is made - we distinguish between payments that function as compensation and are therefore paid to the injured party and those that are paid to a third party; and (c) whether or not the payment was probabilistic - we distinguish between payments that are certain and those that are not.

We conjecture that social norms, cognitive biases, and other forces could cause people to behave differently under legal rules that create similar economic consequences. More specifically, we expect that when the legal payment is done in advance, with certainty and to the party who was harmed by the behavior, the similarity to a price will be greater, leading people to show greater willingness to engage in the harm creating behavior if they find it beneficial. As the legal structure shifts away from the paradigmatic structure of a price, by moving the payment after the fact, adding a probabilistic element to it, and changing the identity of the recipient, people might be less inclined to treat the legal payment as a price, leading them to be less willing to engage in harm creating behavior even if it is in their best interest to do so.

Using a sample of 420 students, we employed a between-subject, three-factor design. Each factor was divided along two levels: timing of payment (ex-ante v. ex post), identity of recipient (state vs. injured party), and level of certainty (certain vs. probable). Participants were randomly divided amongst the six experimental conditions. In each experimental condition, a questionnaire was introduced with a hypothetical scenario that involved the behavior of an owner of a factory that creates a negative externality in its production process. Following the scenario, participants were asked about their likely behavior, as well as their social, legal and moral

${ }^{6} \mathrm{Id}$. at $13-15$.

${ }^{7}$ Id. at 10-13. 
perceptions. Overall, we found that participants were more likely to engage in production when they paid the individual, when they paid in advance and when the payment was not probabilistic.

The article is organized as follows: Part I reviews the relevant background to our study. We outline traditional economic and legal scholarship that treats money in general and legal payments specifically as fungible. We then explore studies that suggest that neither is fungible, and that similar payments could generate different behaviors. Building on these studies, we will suggest several hypotheses as to the differences between legal regimes. Part II describes the design of the experiment and its results. In part III we discuses our results, explore the potential policy implications, and deal with some of the limitations. Finally, in part IV we briefly conclude.

\section{BACKGROUND}

The law sets a menu of reactions to different types of behaviors. Take for example the case of a homeowner who throws a party that creates a nuisance to his neighbors, and assume that the law wants to promote efficiency by causing the homeowner to internalize the harm caused to his neighbors. One can imagine several legal regimes that will achieve this goal. The law could require permits for parties, and grant them after a fee equaling the size of the externality is paid. Alternatively, the law could prohibit parties, and fine homeowners who hold them with a fine equaling the size of the externality. Finally, the law could allow the homeowner's neighbors to sue and collect damages that reflect their harms. In this study, we attempt to measure whether the choice between different legal regimes affects the way people perceive the situation, and as a result the way they behave.

Looking at the body of legal payments, we identify three dimensions that differentiate them. The first is the timing of the payment. While some payments are made prior to the act being regulated (e.g., a fee), others are made after the fact (e.g., a fine). The second is the identity of the party receiving the payment. Some legal payments are made to the injured party while others are made to third parties (e.g., the state). The following table summarizes the way in which legal payments align along the first two dimensions we explore:

TABLE 1: LEGAL PAYMENTS - TIMING OF PAYMENT AND IDENTITY OF RECIPIENT

\begin{tabular}{|c|c|c|}
\hline & Third Party & Injured Party \\
\hline Ex-Ante & Fee & Contract Payment \\
\hline Ex-Post & Fine & Tort Damages \\
\hline
\end{tabular}

A third dimension by which legal payments differ relates to the certainty of their imposition. Ex ante payments are by definition certain, and are therefore not analyzed along this dimension. Ex post payments, on the other hand, are either certain or probabilistic. Returning to the example of the party, while private enforcement might be certain in that setting (note that if the neighbors did not detect the party that 
would imply that no harm was caused), public enforcement will sometimes fail, leading to no payment. Economic analysis has explored how discrete changes in the probability of detection can be dealt with through proper adjustments of sanctions. ${ }^{8}$ We do not aim to explore the effects of such discrete changes. Rather, our focus is on the effect of switching from a regime in which the probability of detection is $100 \%$ to one in which it is lower (be the precise probability as it may).

For economists, the comparison between different legal regimes that set monetary consequences to an act is straightforward. Since all dollars are fungible, and rational individuals aim to maximize the amount of dollars they have, economists generally assume that the legal framing of a payment is irrelevant to the decisions individuals make. For example, the chapter in a leading microeconomics text book dealing with negative externalities describes taxes, subsidies, and private rights, as equivalent from the perspective of the individuals engaging in the regulated activity. ${ }^{9}$ From an economic point of view, these are merely names for the price that needs to be paid for the activity. Building on this assumption, the "seminal insight" of law and economics was that the legal system sets prices for different acts, and that the tools of price theory can be employed in order to predict the way different legal rules will influence peoples' decisions. ${ }^{10}$ Based on this insight, legal economists modeled the incentives created by an array of legal payments. Contract remedies were modeled as prices set by the law for breaching a contract. ${ }^{11}$ Tort compensation was analyzed as a price set for engaging in risky behavior. ${ }^{12}$ Similarly, criminal sanctions were modeled as prices affecting criminals' decision whether to commit a crime. ${ }^{13}$ Later contributions continued this line of thought and modeled the different substitution effects between legal prices. ${ }^{14}$

The positive view of legal payments as prices went hand in hand with the normative claim that when efficiency calls for it, breaching a legal duty while paying the legal price is the desirable mode of action. If legal prices are set in an efficient manner that reflects all of the harms associated with a certain breach of duty, then breaching and paying the price implies a gain in social welfare. In the contractual setting this claim manifested itself in the efficient breach debate. ${ }^{15}$ Easterbrook and

\footnotetext{
${ }^{8}$ SteVen ShaVell, Foundations of ECONOMiC ANALysis OF LAW 502-509 (2004).

${ }^{9}$ Andreu Mas-Colell, Michael D. Whinston, \& Jerry R. Green, Microeconomic TheOry 35159 (1995).

${ }^{10}$ Russell B, Korobkin and Thomas S. Ulen, Law and Behavioral Science: Removing the Rationality Assumption from Law and Economics, 88 CAL. L. REV. 1051, 1054 (2000).

${ }^{11}$ See, e.g., Steven Shavell, Damage Measures for Breach of Contract, 11 BELL J. ECON. 466 (1980); Steven Shavell, The Design of Contract Remedies for Breach, 98 Q. J. ECON. 121 (1984).

${ }^{12}$ See generally GuIDo CALABRESI, THE COSTS OF ACCIDENTS: A LEGAL AND ECONOMIC ANALYSIS (1970); William M. LANDES AND Richard Posner, The ECONOMIC STRUCTURE OF TORT LAW (1987).

${ }^{13}$ See, e.g., Gary S. Becker, Crime and Punishment: An Economic Approach, 76 J. Pol. Econ. (1968) 169, 176-79 (1968) (presenting an analysis of the supply of crime). For a more contemporary treatment of the issue see Isaac Ehrlich, Crime, Punishment, and the Market for Offenses, 10 J. ECON. PERSP. 43 (1996).

${ }^{14}$ See, e.g., Neal Kumar Katyal, Deterrence's Difficulty, 95 MiCH. L. REV. 2385 (1997) (analyzing substitution between types of crimes); Doron Teichman, The Market for Criminal Justice: Federalism, Crime Control and Jurisdictional Competition, 103 MICH. L. REV. 1831 (2005) (analyzing substitution between geographic areas).

${ }^{15}$ See, e.g. Richard Craswell, Contract Remedies, Renegotiation, and the Theory of Efficient Breach, 61 S. CAL. L. REV. 629 (1988); Daniel Friedman, The Efficient Breach Fallacy, 18 J. LEGAL STUD. 1 (1989).
} 
Fischel portray the view of legal payments as prices more generally in the following statement:

The penalties Congress names for disobedience are a measure of how much it wants firms to sacrifice in order to adhere to the rules; the idea of optimal sanctions is based on the supposition that managers not only may but also should violate the rules when it is profitable to do so. ${ }^{16}$

A corollary of the seminal insight is that different legal regimes are merely tools in a policymaker's toolbox, and that the choice between them should be guided by the costs and benefits of administering them, and not by an inherent difference between them. Coase bases his endorsement of property rights over taxation as a way to deal with negative externalities on the assumption that setting the appropriate level of taxation might be a difficult task for the government. ${ }^{17}$ A more detailed analysis of the question was later offered by Shavell, who explored the advantages and disadvantages of different legal regimes aimed at controlling risk. ${ }^{18}$ Shavell divided the different regimes along two of the three dimensions we explore in this study, namely: ex post versus ex ante regimes and regimes that are initiated by private parties compared to those that are controlled by the state. ${ }^{19}$ Discussing the relative advantages of ex post and ex ante regimes, Shavell deals with questions such as do injurers have sufficient resources to pay for the harm they cause? Can specific injurers be identified and assigned liability? Which party possesses information regarding the risk and the ability to reduce it? What are the administrative costs associated with each regime $?^{20}$ Similarly, Shavell's analysis of the private-state dimension focuses on issues like the level of dispersion of harm and the parties' information. ${ }^{21}$ Neither Coase nor Shavell explore the possibility that the legal framing itself will affect the parties' incentives, and thus could affect the selection of the optimal legal regime.

Despite these views, some law and economics scholars have explored the boundary of perceiving legal remedies as prices. Cooter, for instance, distinguished between prices and sanctions based on the nature of the legal rule. ${ }^{22}$ According to Cooter's definition, a sanction "is a detriment imposed for doing what is forbidden," while a price is "payment of money which is required in order to do what is permitted." 23 In other words, sanctions are attached to behaviors that violate a certain standard set by the law, while prices are attached to certain behaviors no matter how they are preformed. Thus, for example, Cooter suggests that liability within a negligence rule is a sanction, while liability created by a strict liability rule is a

\footnotetext{
${ }^{16}$ Frank Easterbrook \& Daniel Fischel, Antitrust Suits by Targets of Tender Offers, 80 MICH. L. REV. 1155, 1177 n.57 (1982).

${ }^{17}$ Ronald H. Coase, The Problem of Social Cost, 3 J.L. \& ECON. 1, 41-42 (1960).

${ }^{18}$ STEVEN SHAVELl, ECONOMIC ANALYSIS OF ACCIDENT LAW 277-290 (1987).

${ }^{19}$ Note that Shavell focused on the identity of the party initiating the legal procedure leading to the payment, while we focus on the party receiving the payment. Analytically the two do not have to be identical given the possibility of decoupling. Nonetheless, usually the party initiating the legal process will also be the party receiving the payment.

${ }^{20}$ Shavell, supra note 18 at 279-82.

${ }^{21} \mathrm{Id}$. at 283-84.

${ }^{22}$ Robert Cooter, Prices and Sanctions, 84 COLUM. L. REV. 1523 (1984).

${ }^{23} I d$. at $1524-25$.
} 
price. ${ }^{24}$ Nonetheless, one should notice that Cooter's distinction between prices and sanctions does not challenge the basic assumption that all legal payments are fungible. According to Cooter, a sanction of $\$ 100$ and a price of $\$ 100$ create identical incentives. Rather, it is the discontinuation in legal liability in a sanctioning system (created by the shift from no liability to total liability when one violates the legal standard) that distinguishes the incentives created by the two systems.

The assumption of fungible legal dollars runs against several bodies of literature. Social scientists have documented many instances in which people do not treat their dollars as fungible. Legal scholars have argued both that different legal payments ought to be viewed as different, and that people in fact view them as different. We turn now to review this literature, and to present its implications to our study.

Sociologists have long since differentiated between different types of monies. In her study, The Social Meaning of Money, Zelizer documents a wide range of situations in which people earmark monies in unique ways. ${ }^{25}$ In early $20^{\text {th }}$ century America, money earned by women was dedicated to specific purposes. ${ }^{26}$ Similarly, a set of social norms limited the way money received as a gift could be used. ${ }^{27}$ For instance, gift money was not to be used for expenses such as grocery shopping or for paying a gambling debt. ${ }^{28}$ Zelizer concludes that people think and feel differently about various types of money, which brings about different uses of these monies. ${ }^{29}$ While this literature provides a theoretical foundation for our study, in the sense that it demonstrates that people do not treat all of their dollars as fungible, it does not provide us with specific hypotheses. Zelizer generally deals with the way people treat money they have, not the way they treat money they must pay. Furthermore, Zelizer does not explore the unique characteristics of legal payments as such.

Some economists have also shifted from the fungibility assumption, documenting its violations ${ }^{30}$ : Graduate students with high expected incomes do not treat present and future dollars as fungible and tend to consume less than the life cycle theory of consumption would suggest. ${ }^{31}$ Dollars that are earmarked by employers as "regular" income or as a "bonus" are consumed differently by households. ${ }^{32}$ People receiving relatively small windfalls tend to consume them in a way that violates rational choice theory. ${ }^{33}$ Much like the sociological literature, we find this line of literature motivating, yet we cannot generate specific hypotheses based on it. Economic studies of the fungibility of money have also focused on money people receive and the way they spend it (in economic terms, economists have measured the

${ }^{24} I d$. at $1538-44$.

${ }^{25}$ Zelizer, supra note 1.

${ }^{26} I d$. at 61-63.

${ }^{27}$ Id. at $111-114$.

${ }^{28} \mathrm{Id}$.

${ }^{29} I d$. at 211.

${ }^{30}$ See generally Thaler, supra note 3 . Psychologists have also explored in experimental settings the limits of the fungibility assumption. See, e.g., Hal R. Arkes et. al., The Psychology of Windfall Gains, 59 Organizational BeHAV. \& HUM. DECISION PROCESSES 331 (1994).

${ }^{31} I d$. at 196.

${ }^{32}$ Tsuneo Ishiwaka \& Kazuo Ueda, The Bonus Payment and Japanese Personal Savings, in THE ECONOMIC ANALYSIS OF THE JAPANESE FIRM (Aoki Masahiko ed., 1984).

${ }^{33}$ Michael Landsberger, Windfall and Consumption: Comment, 56 AM. ECON. REV. 534, 538-9 (1966). 
marginal propensity to consume). They have not measured non-fungibility between different payments, let alone between different types of legal payments.

Non-fungibility of money was documented in the crowding out literature as well. Generally, this literature suggests that external interventions that utilize monetary incentives or punishments may undermine (and under different identifiable conditions strengthen) intrinsic motivations. ${ }^{34}$ For instance, paying people in return for their blood might erode altruistic blood donations. ${ }^{35}$ A refinement of the crowding out literature demonstrated that the framing of incentives affects peoples' behavior. Fehr and Gachter found that when monetary incentives were framed as a price reduction, they had a greater effect than when they were framed as a bonus. ${ }^{36}$ Frey and Stutzer have argued that tradable emission rights and emission taxes could create a different crowding out effect, bringing about different behavior. ${ }^{37}$ This refinement of the crowding-out literature leads us to assume that the legal framing of payments could affect the way in which the law crowds out alternative reasons for action, thereby affecting people's behavior.

An additional line of economic studies that offers more concrete predictions for our study is that dealing with decision making in situations of uncertainty. This literature demonstrated that people tend to prefer certain outcomes over probabilistic ones. ${ }^{38}$ For example, given the choice between 3,000 for sure and 4,000 with $80 \%$ probability, people will tend to choose the certain 3,000. However, when choosing between 3,000 with $25 \%$ probability and 4,000 with $20 \%$ probability, most people choose the 4,000 option, despite the fact that the second set of options is the same as the first with all probabilities reduced by a factor of $4 .^{39}$ The reduction of the probability of winning from 1.0 to 0.25 had a much larger effect than the reduction from 0.8 to 0.2 . $^{40}$ These results imply that shifting from a probabilistic to a certain sanction (while holding the size of the sanction constant) might increase the level of the activity being sanctioned because people will no longer have to deal with the uncertainty associated with the sanction. ${ }^{41}$ Note that this prediction runs against

\footnotetext{
${ }^{34}$ See e.g., Ernst Fehr, Simon \& Gachter, Do Incentive Contract Undermine Voluntary Cooperation?, University of Zurich Working paper 34 (2002); Ernst Fehr \& Armin Falk, ,Psychological Foundations of Incentives, 46 EUR. ECO. REV., 687-724 (2002); Ernst Fehr \& Bettina Rockenbach, Detrimental Effects of Sanctions on Human Altruism, 422 NATURE, 137-140 (2003). For a general review see Bruno S. Frey, Not Just For the MONEy - AN ECONOMic THEORY OF PERSONAL Motivation (1997).

${ }^{35}$ Richard Morris Titmus, The Gift of Relationship: From Human BloOd to Social Policy (1971) (arguing that monetary payments to givers of blood could diminish the amount of blood given voluntarily).

${ }^{36}$ Fehr \& Gachter supra note 34.

${ }^{37}$ Bruon S. Frey \& Alois Stutzer, Environmental Moral and Motivation, University of Zurich Institute for Empirical Research in Economics Working Paper Series 14-16 (2006).

${ }^{38}$ Daniel Kahneman \& Amos Tversky, Prospect Theory: An Analysis of decision under Risk, 47 ECONOMETRICA, 263-291 (1979). Much of Kahneman's and Tversky's analysis is build on the early contribution of Allais in Maurice Allais, Le Comportement de l'Homme Rationnel devant le Risque: Critique des Postulats et Axiomes de l'Ecole Americaine, 21 ECONOMETRICA 503 (1953).

${ }^{39}$ Kahneman \& Tversky, id. at 266-67.

${ }^{40} I d$.

41 It is important to note that the behavioral literature distinguishes between perceptions of risk (when the probability of the event is known) and perceptions of uncertainty (when the probability of the event is unknown). In this study we focus on certain and uncertain enforcement (where participants are not given information on the probability of enforcement), since the theory we focus on is related to the social meaning of enforcement and not on judgment under uncertainty. For a discussion of the
} 
traditional deterrence models, according to which any increase in the probability of detection will necessarily reduce activity levels. The reason for this discrepancy is that traditional theories treated the switch between a probabilistic and a certain regime as merely another "regular" increase in the probability of detection.

Turning to the legal literature, we find several claims made regarding different types of legal payments. The legal philosophy literature has explored in depth the inherent distinction between different types of legal payments. To be sure, the normative nature of the philosophical claims reviewed below renders them distinct from social scientific hypotheses, which are designed to undergo empirical assessment. Thus, one might question the relevance of this literature to an empirical project such as ours. Nonetheless, there are two reasons we find this literature relevant. First, despite the normative-positive dichotomy, legal philosophers build some of their insights on "armchair" sociology and assumptions regarding human intuition. Second, even if the philosophical project is purely normative, one would expect to observe some type of correlation between what constitutes normatively desirable behavior and actual behavior.

Up untill the 1960s, Anglo-American legal philosophy focused on the role of sanctions in creating legal obligations. For instance, John Austin viewed law as a set of commands created by a sovereign and backed by sanctions. ${ }^{42}$ This line of thought supports the law as a price setting device view endorsed by legal economists. Yet, later legal philosophers have presented a competing view as to the role of law within the process of reasoning. In The Concept of Law, H. L. A. Hart presented what is seen as a successful critic of Austin's command theory of law. ${ }^{43}$ As Hart pointed out, legal rules are not simply a set of rules backed by sanctions. ${ }^{44}$ Rather, the body of law includes an array of enabling regimes that are not built on sanctions. ${ }^{45}$ In addition, Hart emphasized the role of obligations created by law. This analysis led Hart to distinguish between taxation and fines as means to achieve social control. As he put it, "[a] punishment for a crime, such as a fine, is not the same as a tax on a course of conduct, though both involve directions to officials to inflict the same money loss. What differentiates these ideas is that the first involves, as the second does not, an offence or breach of duty in the form of a violation of a rule set up to guide the conduct of ordinary citizens." 46 Hart's analysis captures the intuition that different types of legal payments are inherently different since they embody a different moral meaning.

Raz offers a different account of the role of norms. ${ }^{47}$ Raz distinguishes between first-order and second-order reasons for actions. First-order reasons refer to a simple weighing of the different considerations to act in a certain manner. ${ }^{48}$ Second order reasons, on the other hand, guide the decision maker how to combine first order

difference between risk and uncertainty see Amos Tversky \& Craig R. Fox, Weighing Risk and Uncertainty 102 PSYCH. REV., 269 (1995).

${ }^{42}$ John AUSTIN, THE PROVINCE OF JURISPRUDENCE DETERMINED (Wilfrid E. Rumble, ed. 1995).

${ }^{43}$ H. L. A. HART, THE CONCEPT OF LAW (1961).

${ }^{44} I d$. at $26-41$.

${ }^{45} \mathrm{Id}$.

${ }^{46}$ Id. at 39.

${ }^{47}$ See generally JOSEPH RAZ, PRACTICAL REASON AND NORMS (1975).

${ }^{48} I d$. at $35-48$. 
reasons. ${ }^{49}$ According to Raz, legal rules requiring performance (or omission) of an act function as exclusionary second order norms, which exclude from deliberation reasons that are not legal norms or legally recognized norms. ${ }^{50}$ Notice that this analysis suggests that behavior should not be affected by the size of the expected sanction, since the price of the act is an excluded reason. ${ }^{51}$ Raz also points out that some legal rules function as permissive rules. ${ }^{52}$ These laws actually function as a permission to perform the act, and exclude from deliberation reasons not to act that are not legal norms or legally recognized reasons. Note that within this legal framework, one would expect to observe sensitivity to the expected sanction set by the law, since prices are not an excluded reason in this context.

A second strand of legal scholarship our study relates to is that dealing with the expressive power of law. Expressive theories consist of an array of distinct claims, including theories of lawmaking, claims about the connection between the law and social norms, and positive predictions as to the way different legal expressions affect behavior. ${ }^{53}$ Our focus here is on the expressive theories of sanctions. Expressive theories of sanctions argue that, as a descriptive matter, one should distinguish between penalties and punishments. ${ }^{54}$ While penalties function to a large degree as prices, punishments include a deeper social meaning that express resentment and indignation. ${ }^{55}$ Thus, when legal payments are framed as punishments, the power of the law to regulate behavior is greater. An example of the way expressive theories of sanctions have played out in policy debates can be found in the different views presented regarding the use of emission trading. Economists generally view emission trading as an efficient way to allocate polluting rights. ${ }^{56}$ Legal environmentalists, on the other hand, have raised the concern that emission trading will function as a price, and lead to a greater degradation of the environment. ${ }^{57}$

The expressive literature has yet to offer a systematic analysis of legal payments that can explain what precisely distinguishes between penalties and punishments. One recurring theme in this literature is that criminal sanctions carry a

\footnotetext{
${ }^{49} I d$.

${ }^{50} \mathrm{Id}$. at $141-46$.

${ }^{51}$ Lewis Kornhauser, The Normativity of Law, 1 AM. L. \& ECON. REV. 3,9 (1999).

${ }^{52}$ Raz, supra note 47 at 141-46.

${ }^{53}$ For some prominent examples of this literature see, e.g., Richard H. Pildes \& Elizabeth S. Anderson, Slinging Arrows at Democracy: Social Choice Theory, Value Pluralism, and Democratic Politics, 90 Colum. L. REV. 2121 (1990); Cass R. Sunstein, On the Expressive Function of Law, 144 U. PA. L. REV. 2021 (1996); Dan M. Kahan, What Do Alternative Sanctions Mean?, 63 U. CHI. L. REV. 591 (1996). For a critical view see, e.g., Matthew D. Adler, Expressive Theories of Law: A Skeptical Overview, 148 U. PA. L. REV. 1363 (2000). For empirical studies of the expressive function of the law see Iris Bohnet \& Robert D. Cooter, Experimental Analysis of Expressive Law and Economics, (2000) (Working Paper, UC Berkeley); Yuval Feldman, The Expressive Function of the Law: Legality, Cost, Intrinsic Motivation and Consensus, [unpublished manuscript on file with the authors]; Richard $\mathrm{H}$. McAdams \& Janice Nadler, Testing the Focal Point Theory of Legal Compliance: Expressive Influence in an Experimental Hawk/Dove Game, 2 J. EMPIRICAL LEGAL STUD. 87 (2005).

${ }^{54}$ See Joel Feinberg, The Expressive Function of Punishment, 49 MONIST 397 (1965), reprinted in JOEL FEINBERG, DOING AND DESERVING 95 (1970).

${ }^{55}$ Feinberg, id. at 97-98.

${ }^{56}$ Bruce A. Ackerman \& Richard B. Stewart, Reforming Environmental Law: The Case for Market Incentives, 13 COLUM. J. ENVTL. L. 171 (1988).

57 See, e.g., Sunstein, supra note 53 at 2045-46; Steven Kelman, What Price InCEntives? ECONOMISTS AND THE ENVIRONMENT (1981).
} 
powerful expressive force when compared to other forms of sanctioning. ${ }^{58}$ In our framework, this would imply that a combination of an ex-post probabilistic payment with the state as the recipient of the payment carries a social meaning that gives it greater deterrent power. Yet, it is not clear if it is the combination of all of these that creates the unique social meaning, or if each characteristic creates the meaning on its own. We conjecture that it is the first two that carry the expressive social meaning. Probabilistic payments might imply an element of wrongdoing on the part of the paying party. One does not "get caught" or "get away" if one engages in socially legitimate activities. It is only wrongdoers engaging in blameworthy behavior who "get caught." Ex post payments might have a similar meaning since they are payments that are forced upon the actor by the state. Ex ante payments, on the other hand, are made with consent, which could imply no wrongdoing on behalf of the paying party. Regarding the identity of the party receiving the payment, it is difficult to see a necessary conclusion to be drawn. The state clearly has strong expressive powers, but those could be used both to prohibit and to legitimize an act. Thus, we cannot assume that paying the state will always carry an identical expressive meaning. However, given that both the difference in time and difference in probability are two qualities that differentiate fines from prices, we might expect that this effect will be greater for the state. It seems that when the recipient of the money is the state, and when the payment is dependent upon getting caught, the payment will look like a fine rather than a price. Similarly, paying the state in advance may foster a presumption of legality, as if the state has licensed the behavior in question. Thus, we expect to see some interaction between these three factors, where time and certainty will exert a greater effect when the recipient of the payment is the state, rather than the individual.

A final body of scholarship we draw from is the incommensurability literature. ${ }^{59}$ Sunstein defines incommensurability as a situation in which "the relevant goods cannot be aligned along a single metric without violence to our considered judgments about how these goods are best characterized."60 Unlike the utilitarian claim that decisions can be aligned along a utility metric, and the economic assumption that decisions can be evaluated through a monetary metric, the incommensurability view holds that some types of decisions do not reflect a preference of one value over the other. In the context of compensatory damages, incommensurability suggests that they do not function as a price. ${ }^{61}$ Rather, they are intended to acknowledge wrongdoing on the part of the wrongdoer, and to bring redress to victims by showing that their rights are taken seriously. ${ }^{62}$ Thus, this literature suggests that in a compensatory setting the payment of damages encompasses a moral content not present in other settings. This content might discourage people from conducting a simple cost benefit analysis because they do not

\footnotetext{
${ }^{58}$ Feinberg, supra note 54; Richard H. McAdams, The Origin, Development, and Regulation of Norms, 96 Mich. L. REV. 338, 397-400 (1997).

${ }^{59}$ For important contributions to the philosophical literature on incommensurability see ELIZABETH ANDERSON, VALUE IN ETHICS AND ECONOMICs (1993); JosePH RAZ, THE MORALiTY OF FreEdOM 322 (1986). Later legal implications of the concept were discussed in Cass R. Sunstein, Incommensurability and Valuation in Law, 92 Mich. L. REV. 779 (1994); MARGARET JANE RADIN, CONTESTED COMMODITIES (1996).

${ }^{60}$ Sunstein, id. at 796 .

${ }^{61}$ See Margaret Jane Radin, Compensation and Commensurability, 43 DUKE L.J. 56 (1993); Sunstein, id. at 840-43.

${ }^{62}$ Radin, id. at 61.
} 
see the dollars they pay as damages on the same metric as the harm caused to the injured party.

In sum, we have identified three structural dimensions that differentiate legal payments: timing, recipient identity, and certainty. Reviewing the literature has led us to conclude that, even when legal payments are structured such that their economic consequences are similar, they might be perceived by people as different. These differences, in turn, may yield different behavior patterns. With this background in hand, we turn to explore these differences.

\section{THE EXPERIMENT}

\section{Participants and Design}

A total of 420 students at Bar-Ilan University and the Hebrew University of Jerusalem completed the questionnaire. The participants were not familiar with the legal issues that were described in the questionnaire. We employed a between-subject, three-factor design. Each factor was divided along two levels: timing of payment (exante vs. ex post), identity of recipient (state vs. injured party), and level of certainty (certain vs. probable).

\section{Procedure}

Participants were randomly divided amongst the six experimental conditions. The questionnaire was introduced with a hypothetical scenario that involved the behavior of an owner of a factory that creates a negative externality in its production process. The text of the questionnaire, distributed to all subjects, read as follows (In Hebrew; for a translation of the full questionnaire see appendix):

"Assume that you own a fertilizer factory located adjacent to a small lake. You recently received an order for fertilizer, which the factory has not produced previously. It will cost the factory 200,000 Shekels [around $\$ 50,000$ ] to produce the order. Producing this particular fertilizer also involves dumping a new kind of chemical into the lake. The only effect of dumping this chemical into the lake will be to raise the production expenses of a neighboring fertilizer factory, which is also located at the edge of the same lake. With the exception of the neighboring factory, the lake water is not used by anyone else. Additionally, the new chemical does not cause any medical problems or damage to the environment."

The first sub-group was told that, according to the law, in order to dump the chemical they need to pay a license fee of 100,000 Shekels (around \$25,000), ex-ante (henceforth: Ex-ante-state).

The second sub-group was told that, according to the law, in order to dump the chemical they need to pay the neighboring factory a sum of 100,000 Shekels (henceforth: Ex-ante-Individual).

The third sub-group was told that, according to the law, if they dump the chemical they are sure to be sued by the neighboring factory, and are expected to pay a sum of 100,000 Shekels (henceforth: Ex-post-Individual-certain). 
The fourth sub-group was told that, according to the law, if they dump the chemical they might be sued by the neighboring factory, and that if they are sued they are expected to pay a sum of 100,000 Shekels (henceforth: Ex-post-Individualprobable).

The fifth sub-group was told that, according to the law, if they dump the chemical they will be fined 100,000 Shekels by the municipal authority. Participants in that group were told that due to some state of the art equipment detection of dumping is certain (Henceforth: Ex-post-State-certain).

The sixth sub-group was told that, according to the law, if they dump the chemical there is a good chance that they would be sued by the authorities and would have to pay a fine of 100,000 Shekels by the municipal authority (Henceforth: Ex-post-Stateprobable).

The seventh sub-group served as a control and did not undergo any manipulation.

Following the short presentation of the vignettes, participants were asked to estimate the sum of money they would ask for in order to produce the chemical. ${ }^{63} \mathrm{In}$ addition, we asked participants about the perceived ethicality of producing the chemical, whether they thought that producing the chemical was the right move for them, whether it was legally permissible to do so, and finally, about the likelihood that in this given situation they would engage in producing the chemical. (For the full questionnaire see appendix).

\section{Results}

\section{A. Differences Between 'Legal Dollars'}

In order to compare the groups, they were divided according to two criteria: a) the entity receiving the sum of 100,000 NIS, where one category relates to the State (Groups 1, 5, and 6) and the second to the individual (Groups 2, 3, and 4); b) the certainty of payment and time of payment, where one category relates to certain payment ahead of time (groups 1 and 2, heretofore Ex ante), a second to certain payment after the fact (Groups 3 and 5, heretofore, Ex-post), and a third to uncertain payment after the fact (Groups 4 and 6, heretofore, Ex-post probable). ${ }^{64}$ After this, a series of 2-Way Analyses of Variance (ANOVA, 2 X 3) were performed (payment receiving entity $\mathrm{x}$ certainty of payment and time) ${ }^{65}$ The dependent variables, each

\footnotetext{
${ }^{63}$ Given that the money people asked for could be dictated by a large number of factors, and that the definition of what is a large sum of money might vary from one person to another, we supplemented this question with an explicit question of whether they think they should ask for a large sum of money in order to produce the fertilizer. For further discussion see infra notes Error! Bookmark not defined. - 130 and accompanying text.

${ }^{64}$ As a result of this, two new 2 or 3-level independent variables were created

${ }^{65}$ ANOVA is a very common statistical technique, which aims to identify the sources of variance among participants. In our design, the purpose of the statistical analysis is to examine whether the experimental groups are different from each other. The procedure allows us to tell how much of the difference between participants could be attributed to the assignment to the different sub-groups. In
} 
checked separately, were the six attitude variables. ${ }^{66}$ The independent variables were the following: a) the entity that received the payment, and b) the certainty of the payment and time of that payment. ${ }^{67}$ Table 2 presents the means and standard deviations of each of the variables, divided by the six sub-groups. ${ }^{68}$ Following the table we describe the findings of the ANOVAs performed for each variable separately.

TABle 2: MEANS AND STANDARD DEVIATION OF ALl MEASURED DEPENDENT VARIABLES Divided By THE IDENTITY OF THE RECIPIENT, CERTAINTY OF THE PAYMENT AND ITS TIMING

\begin{tabular}{|l|c|c|c|c|c|c|c|c|c|c|c|c|}
\hline & \multicolumn{4}{|c|}{ State } & \multicolumn{4}{c|}{ Individual } \\
\hline & $\begin{array}{c}\text { Ex Ante } \\
\text { Certain }\end{array}$ & \multicolumn{2}{c|}{$\begin{array}{c}\text { Post } \\
\text { Certain }\end{array}$} & \multicolumn{2}{c|}{$\begin{array}{c}\text { Post } \\
\text { Probable }\end{array}$} & \multicolumn{2}{c|}{$\begin{array}{c}\text { Ex Ante } \\
\text { Certain }\end{array}$} & \multicolumn{2}{c|}{$\begin{array}{c}\text { Post } \\
\text { Certain }\end{array}$} & \multicolumn{2}{c|}{$\begin{array}{c}\text { Post } \\
\text { Probable }\end{array}$} \\
\hline Variable & M & SD & M & SD & M & SD & M & SD & M & SD & M & SD \\
\hline Unethical & 4.59 & 3.11 & 6.12 & 3.01 & 7.06 & 2.35 & 4.17 & 2.58 & 5.04 & 2.38 & 6.40 & 2.70 \\
\hline Appropriateness & 6.10 & 3.06 & 4.53 & 2.79 & 4.78 & 2.79 & 6.54 & 2.56 & 5.79 & 2.60 & 5.39 & 2.84 \\
\hline Personal Gain & 6.27 & 3.24 & 4.97 & 2.89 & 5.06 & 2.66 & 6.53 & 2.11 & 6.27 & 2.79 & 5.45 & 3.15 \\
\hline $\begin{array}{l}\text { Legality } \\
\text { Perception }\end{array}$ & 3.42 & 2.63 & 8.19 & 2.42 & 8.45 & 2.23 & 3.74 & 2.60 & 5.23 & 3.08 & 6.34 & 3.24 \\
\hline Compliance & 5.03 & 3.27 & 3.94 & 2.80 & 4.41 & 3.07 & 6.12 & 2.54 & 5.70 & 3.09 & 4.77 & 3.09 \\
\hline Entitlement & 6.60 & 2.64 & 7.71 & 2.13 & 7.97 & 1.70 & 7.02 & 1.84 & 7.14 & 1.97 & 7.85 & 1.81 \\
\hline
\end{tabular}

\section{1) Un-ethicality}

The measure of un-ethicality and the next measure of appropriateness both focus on the perception of the morality of producing the fertilizer in a given legal payment setting. We first examined the between-group perceived level of unethicality of fertilizer production. ${ }^{69}$ In the analysis of variance a significant ${ }^{70}$ difference was found between the averages based on the identity of the party receiving the payment. ${ }^{71}$ The average of the individual was significantly lower than the average of the state. ${ }^{72}$ That is to say, when the payment was made to the

plain words, the statistical analyses will tell us how much of the differences in the responses of participants could be explained by the framing of the legal payment.

${ }^{66}$ Dependent variable refers to the variables that are explained by the model. In our context, the dependent variables are participants' attitudes toward the production of the fertilizer.

${ }^{67}$ Independent variable refers to the variable that is manipulated in the model in order to measure the effects of the manipulation on the dependent variable. In our context, the independent variables are the various legal regimes we described in the questionnaire.

${ }^{68}$ Standard Deviation (SD) is a common concept used to measure the distribution of a variable around the average.

${ }^{69}$ Ratings for the variable of perceived un-ethicality of fertilizer production (UNETHICAL) ranged from 1 = fertilizer production within the described legal framework is not unethical, and $10=$ fertilizer production within the described legal framework is unethical. Table 2 presents the averages and standard deviations (in parentheses) of the variable of un-ethicality judgment of fertilizer production according to the sum-receiving entity (state and individual) and the time of payment and amount of certainty.

${ }^{70}$ Significance in statistics refers to the odds that a certain result was created by chance. In the context of this paper, every time a difference or a result is presented as Significant, it means that there is less than $5 \%$ likelihood that this difference was coincidental. The 5\% level of significance is a common threshold used in statistical analysis. In some cases where the result was stronger we added $\mathrm{p}<.01$ to imply that the likelihood of a chance driven result was lower than $1 \%$.

${ }^{71} \mathrm{~F}(1,387)=6.81, \mathrm{p}<.01, \eta 2=.02$

${ }^{72}$ The results of the individual were $\mathrm{M}=5.30, \mathrm{SD}=2.71$, while the results of the state were $\mathrm{M}=5.92$, $\mathrm{SD}=3.01$. 
individual, judgment of fertilizer production un-ethicality was lower than when the payment was made to the state.

Similarly, a significant difference was found in the ANOVA between the time of payment and the certainty of payment, ${ }^{73}$ where the average of group 1 (ex-ante certain) was the lowest, after which comes the average of group 2 (ex-post certain) and the average of group 3 (ex-post uncertain). ${ }^{74}$ In the Duncan Post-Hoc Tests, ${ }^{75}$ significant differences were found between the groups. That is to say, when the payment was certain and before hand, un-ethicality judgments were the lowest. Shifting payments to after the fact caused a rise in un-ethicality judgments, and adding a dimension of uncertainty to the payment caused another rise in unethicality. ${ }^{76}$

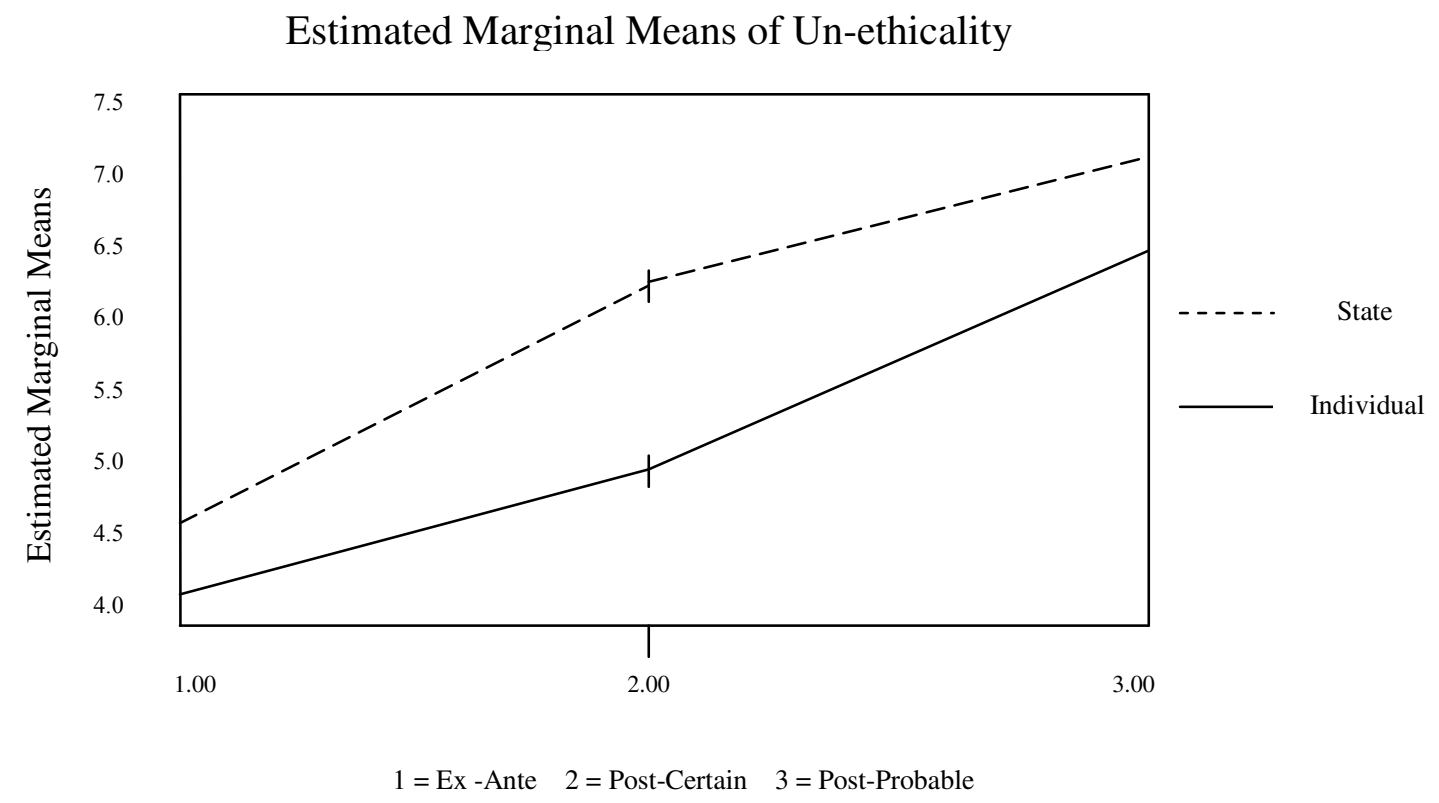

Explanation for the graph (applicable to all of the following graphs)

1. Certain payment and in advance (groups 1 and 2; heretofore, Ex Ante), in the legal situation in which payment for the spillage is certain and paid in advance.

2. Certain payment and after the fact (groups 3 and 5; heretofore, Ex Post Certain), in the legal situation in which payment for the spillage is certain and paid after the fact.

3. Uncertain payment and after the fact (groups 4 and 6; heretofore, Ex Post Probable), in the legal situation in which payment for the spillage is uncertain and paid in after the fact.

${ }^{73} \mathrm{~F}(2,387)=24.82, \mathrm{p}<.001, \eta 2=.11$

${ }^{74}$ The average of group 1 (ex-ante certain) $(\mathrm{M}=4.40, \mathrm{SD}=2.88)$; Group 2 (ex-post certain) (M=5.59, $\mathrm{SD}=2.76)$; Group 3 (ex-post uncertain) $(\mathrm{M}=6.72, \mathrm{SD}=2.55)$.

${ }^{75}$ Post-Hoc tests are used to identify the source of variance when more than one possibility exists. For example, when an effect of variable with three levels is significant, one needs to do a post-hoc test to identify which of the difference between the levels is responsible for the existence of a significant difference. Unless mentioned otherwise, the post-hoc test we chose to use in this paper is called Duncan.

${ }^{76}$ No significant interaction was found between the variable of un-ethicality judgment of fertilizer production (spillage) and the payment recipient (state, individual) in time of payment and certainty of payment $(\mathrm{p}>.05)$. That is to say, the differences that were found between averages of state and individual in the variable of un-ethicality judgment of fertilizer production (spillage) were not related to time or certainty of payment. 


\section{2) Appropriateness}

We next turn to examine the differences between groups in the variable of judgment of fitting market behavior (APPROPRIATENESS). ${ }^{77}$ In the analysis of variance, a significant difference was found between the averages of the variable of payment recipient, ${ }^{78}$ where the average of state was significantly lower than the average of the individual. ${ }^{79}$ That is to say, the appropriateness of production was judged to be lower when the state was the payment recipient compared to the experimental groups where the individual was the payment recipient. Similarly, a significant difference was found in the ANOVA between the averages of the variable of timing and certainty of payment ${ }^{80}$, where the average of group 3 (Ex Post Probable) was the lowest, after which came group 2 (Ex Post Certain), followed by group 1 (Ex Ante Certain) ${ }^{81}$ In the Post-Hoc Tests, it was found that the averages of group 2 and 3 were significantly lower ${ }^{82}$ than the average of group 1 . In other words, shifting the payment to after the fact caused participants to perceive production as a less appropriate choice. $^{83}$

\footnotetext{
${ }^{77}$ The range of ratings in the variable of judgment of fitting market behavior in fertilizer production (APPROPRIATENESS) ranged from $1=$ fertilizer production within the described legal situation is inappropriate market behavior, to $10=$ fertilizer production within the described legal situation is appropriate market behavior. Table 2 presents the averages and standard deviations of the variable of judgment of fitting market behavior in fertilizer production according to payment recipient, time of payment, and certainty of payment.

${ }^{78} \mathrm{~F}(1,386)=7.49, \mathrm{p}<.01,02=\eta 2$.

${ }^{79}$ The results of the state were $\mathrm{M}=5.15, \mathrm{SD}=2.95$ while the results of the individual were $\mathrm{M}=5.87$, $\mathrm{SD}=2.71$.

${ }^{80} \mathrm{~F}(2,386)=7.88, \mathrm{p}<.001 \eta 2=.04$.

${ }^{81}$ The average of group 1 (ex-ante certain) $(\mathrm{M}=6.30, \mathrm{SD}=2.84)$; Group 2 (ex-post certain) $(\mathrm{M}=5.16$, $\mathrm{SD}=2.76)$; Group 3 (ex-post uncertain) $(\mathrm{M}=5.09, \mathrm{SD}=2.82)$.

${ }_{83}^{82} \mathrm{p}<.05$

${ }^{83}$ No significant interaction was found for the variables of judgment of fitting market behavior regarding fertilizer production, according to payment recipient (state, individual) and time and certainty of payment ( $p>.05)$. That is to say, the differences found between averages of state and individual for judgment of fitting market behavior, were not related to time or certainty of payment.
} 


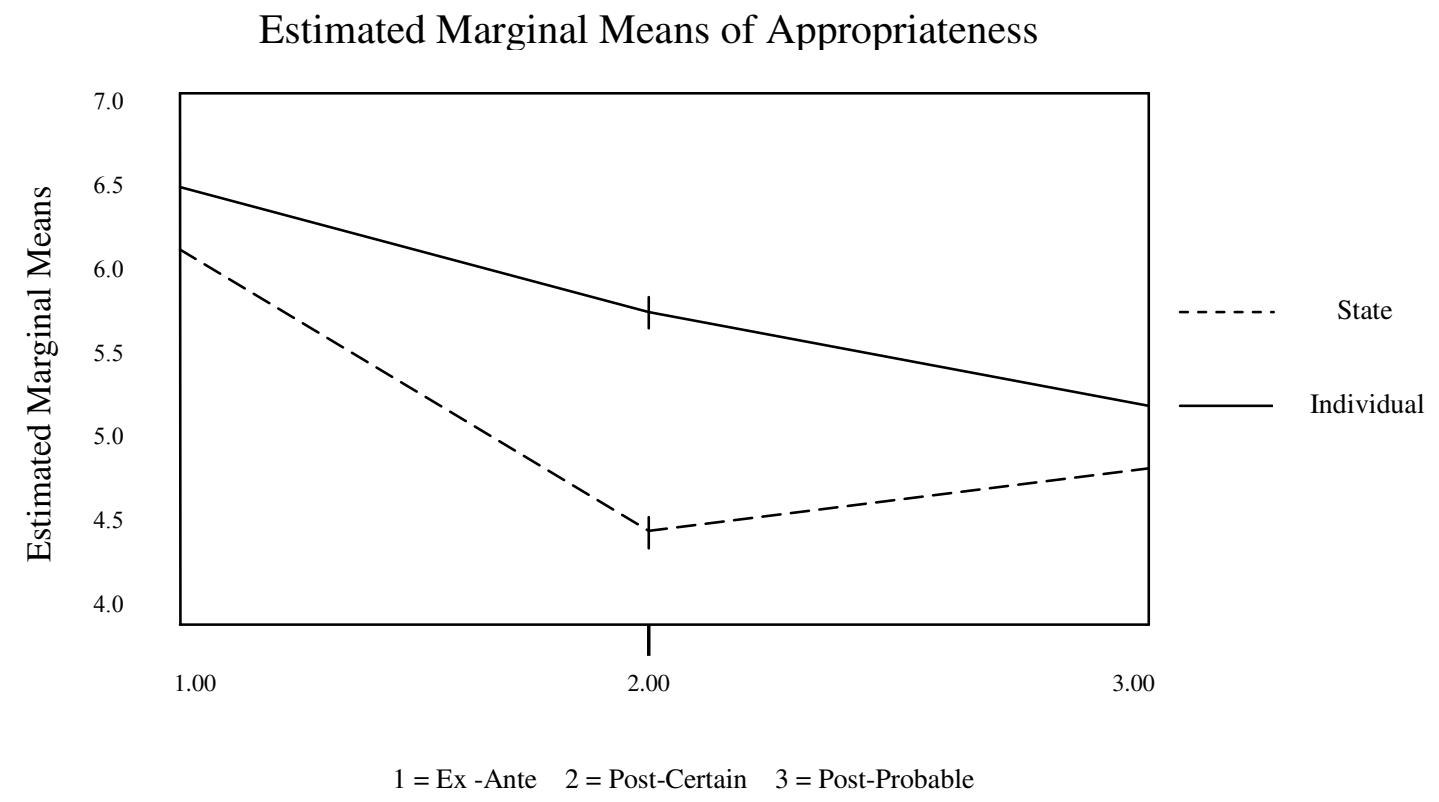

\section{3) Personal Gain}

The third measure examined the differences between groups in the variable of judgment of the perceived personal gain in producing the fertilizer (PERSONAL GAIN). ${ }^{84}$ This item prompted participants to judge on instrumental grounds, whether engaging in that behavior and paying the legal payment is a rational move. In the analysis of variance, a significant difference was found between the averages of the variable of payment recipient source, ${ }^{85}$ where the average of state was significantly lower than the average of the individual. ${ }^{86}$ That is to say, when the state was presented as the payment recipient judgment of personal gain in production was lower than the individual was presented as the payment source. Similarly, the ANOVA revealed a significant difference between the averages of time and certainty of payment ${ }^{87}$, where the average of group 3 (Ex Post Probable) was the lowest, the next highest was group 2 (Ex Post Certain) and the next was group 1 (Ex Ante, Certain). ${ }^{88}$ Post Hoc Tests revealed that the averages of group 2 and 3 were significantly lower than the average of group $1 .^{89}$ That is to say, in the legal situation in which payment was Ex Post

\footnotetext{
${ }^{84}$ The range of ratings for the variable of judgment of the perceived personal gain in producing the fertilizer (PERSONAL GAIN) ranged from $1=$ fertilizer production within the described legal situation is not a personally gainful step, and $10=$ fertilizer production within the described legal situation is a personally gainful step. Table 1 presents the means and standard deviations (in parentheses) for the variable of judgment of the perceived personal gain in producing the fertilizer, as a function of the payment recipient source and time and certainty of payment.

${ }^{85} \mathrm{~F}(1,384)=5.07, \mathrm{p}<.05, \eta 2=.01$.

${ }^{86}$ The average of state was $(M=5.43, S D=2.98)$ and the average of the individual was $(M=6.04$, $\mathrm{SD}=2.78)$.

${ }^{87} \mathrm{~F}(2,384)=5.42 \mathrm{p}<.01, \eta 2=.03$.

${ }^{88}$ The average of group 3 (Ex Post Probable) $(\mathrm{M}=5.26, \mathrm{SD}=2.91)$; group 2 (Ex Post Certain) (M=5.61, $\mathrm{SD}=2.91)$ and group 1 (Ex Ante, Certain) $(\mathrm{M}=6.39, \mathrm{SD}=2.77)$.

${ }^{89} \mathrm{P}<.05$.
} 
Probable or Ex Post Certain, fertilizer production was judged to be less personally gainful than when the legal situation was Ex Ante Certain. ${ }^{90}$

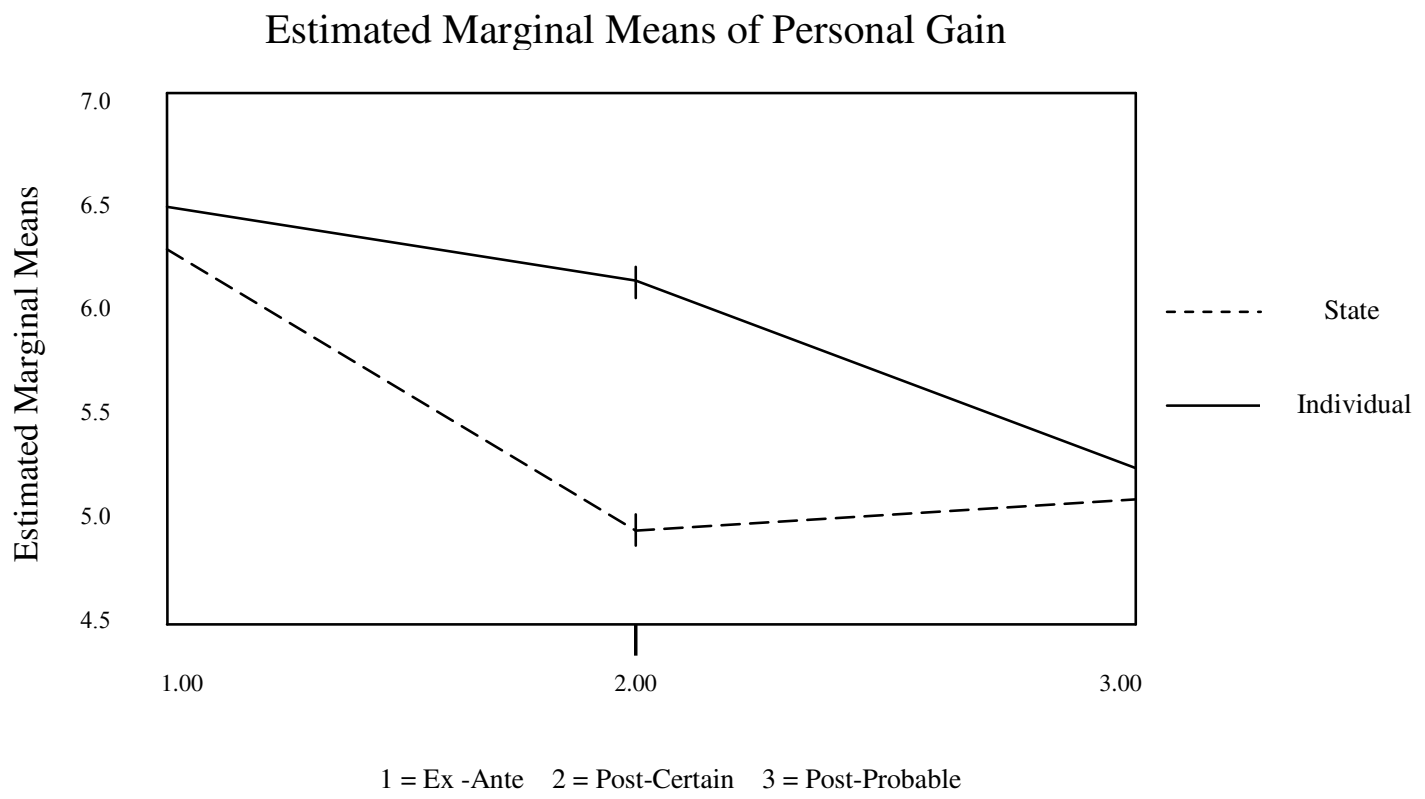

\section{4) Perception of Legality}

The Fourth measure examined the differences between groups for variable of judgment of perceived unlawfulness of fertilizer production (PERCEPTION of LEGALITY). ${ }^{91}$ The purpose of this measure was to examine, whether participants viewed the legal payment as legitimizing their behavior, and making it in accordance with the law. The ANOVA revealed a significant difference between the averages of the variable of payment recipient, ${ }^{92}$ where the average of the individual was significantly lower than average of the state. ${ }^{93}$ That is to say, when the individual was presented as the payment recipient, subjects judged production to be more lawful than when the state was presented as the payment recipient. Similarly, the ANOVA revealed a significant difference between the averages of timing and certainty of payment, ${ }^{94}$ where the average of group 1 (Ex Ante Certain) was lowest, after which came the average of group 2 (Ex Post Certain) and after that the average of group 3

\footnotetext{
${ }^{90}$ No significant interaction was found for the variable of judgment of personal gain in producing the fertilizer, according to payment recipient (state, individual) and time and certainty of payment ( $\mathrm{p}>.05$ ). That is to say, the differences found between averages of state and individual for judgment of personal gain in producing the fertilizer were not related to time or certainty of payment.

${ }^{91}$ The range of ratings for the variable of judgment of perceived unlawfulness of fertilizer production (LEGALITY PERCEPTION) ranged from 1 = fertilizer production within the described legal situation is lawful, and $10=$ fertilizer production within the described legal situation is unlawful. Table 1 presents the averages and standard deviations (in parentheses) of the variable of judgment of perceived unlawfulness of fertilizer production as a function of the payment recipient source and time and certainty of payment.

${ }^{92} \mathrm{~F}(1,380)=28.85, \mathrm{p}<.001, \eta 2=.07$.

${ }^{93}$ The average of the individual was $(M=5.19, S D=3.18)$ and the average of the state was $(M=6.59$, $\mathrm{SD}=3.44)$.

${ }^{94} \mathrm{~F}(2,380)=76.62, \mathrm{p}<.001, \eta 2=.29$.
} 
(Ex Post Probable). ${ }^{95}$ Post Hoc Tests revealed that the average of group 1 was significantly lower than the averages of group 2 and 3, which were not significantly different. In other words, shifting the payment to after the fact caused participants to perceive production as less lawful.

In contrast to all other measures, a significant interaction ${ }^{96}$ was found for the variable of perceived unlawfulness of production and payment recipient according to time and certainty of payment. ${ }^{97}$ It appears that for group 1 (Ex Ante Certain) a significant difference was not found between the averages of state and individual. ${ }^{98}$ However, significant differences between state and individual were found for group 2 (Ex Post Certain), ${ }^{99}$ and group 3 (Ex Post Probable), for which the averages of state were significantly higher than the averages of individual. The pattern of findings shows that the perception of lawfulness of production when the individual is presented as the payment recipient is higher than when the state is presented as the payment recipient. These disparities were only found when the payment was Ex Post Certain or Ex Post Probable, but not when it was Ex Ante Certain. ${ }^{100}$

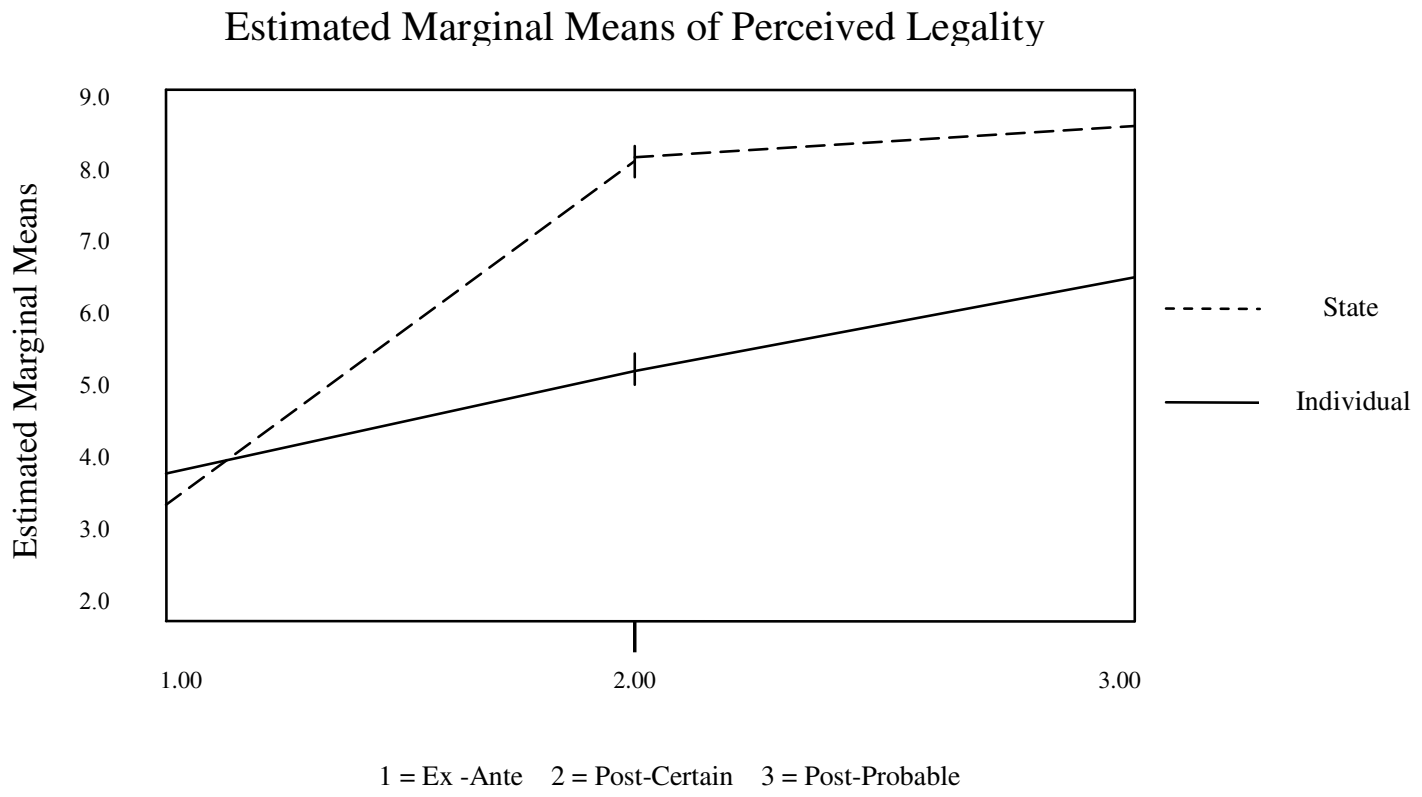

${ }^{95}$ The average of group 1 (Ex Ante Certain) $(\mathrm{M}=3.42, \mathrm{SD}=2.62)$; group 2 (Ex Post Certain) (M=6.77, $\mathrm{SD}=3.12)$; group 3 (Ex Post Probable) $(\mathrm{M}=7.39, \mathrm{SD}=2.97)$.

${ }^{96}$ The meaning of an interaction between the recipient and the time and certainty is that the differences that were found between the averages of state and individual in the variable of perceived unlawfulness of production were moderated by the conditions of time and certainty of payment. The question of who received the money affected the importance of timing and certainty to the perceived unlawfulness of the production.

${ }^{97} \mathrm{~F}(2,380)=14.33, \mathrm{p}<.001, \eta 2=.07$.

${ }^{98} \mathrm{~F}(1,380)=1.44, \mathrm{p}>.05, \eta 2=.00$.

${ }^{99} \mathrm{~F}(1,380)=36.29, \mathrm{p}<.001, \eta 2=.09$.

100 The analysis demonstrates that there are significant differences between the averages of all three groups for time and certainty of payment, between when the payment recipient is the state $\mathrm{F}(2,380)=80.68, \mathrm{p}<.001, \eta 2=.30$, and when the payment recipient is the individual $\mathrm{F}(2,380)=14.41$, $\mathrm{p}<.001, \eta 2=.07$, where the strength of effect was more pronounced in the former. 


\section{5) Intention to Produce}

The fifth measure was related to the differences between groups for the variable of intention to produce compliance to fertilizer production (comply). ${ }^{101}$ Intention to behave was shown in many previous studies to be the best proxy for behavior, ${ }^{102}$ and hence in the context of this study it is the closest approximation of people's actual behavior. The ANOVA revealed a significant difference between the averages of the payment recipient, ${ }^{103}$ where the average of the state was significantly lower than the average of the individual. ${ }^{104}$ That is to say, when the state was presented as the payment recipient, subjects were less willing to produce the fertilizer compared to when the individual was presented as the payment recipient.

Similarly, the ANOVA revealed a significant difference between the averages of timing and certainty of payment, ${ }^{105}$ where the average of group 3 (Ex Post Probable) was the lowest, after which came group 2 (Ex Post Certain) followed by the average of group 1 (Ex Ante Certain). ${ }^{106}$ The Post Hoc Tests revealed that the average of group 3 was significantly lower than group 1 . The average of group 2 was not significantly different than the other groups. In other words, shifting from an ex ante regime to an ex post probabilistic regime reduced the amount of participants willing to engage in production. ${ }^{107}$

\footnotetext{
${ }^{101}$ The range of scores for the variable of compliance to fertilizer production ranged from $1=\mathrm{I}$ would try not to produce the fertilizer within the described legal situation, to $10=\mathrm{I}$ would try to produce the fertilizer within the described legal situation. Table 1 displays the averages and standard deviations (in parentheses) of the variable of compliance to fertilizer production, as a function of the payment recipient source and time and certainty of payment.

${ }^{102}$ See Icek Ajzen, From Intentions to Actions: A Theory of Planned Behavior, in ACTION-CONTROL: FROM COGNITION TO BEHAVIOR 11 (J. Kuhl \& J. Beckman eds, 1985).

${ }^{103} \mathrm{~F}(1,384)=12.43, \mathrm{p}<.001, \eta 2=.03$.

104 The average of the state was $(\mathrm{M}=4.46, \mathrm{SD}=3.08)$ and the average of the individual was $(\mathrm{M}=5.48$, $\mathrm{SD}=2.98)$.

${ }^{105} \mathrm{~F}(2,384)=3.78 \mathrm{p}<.05, \eta 2=.02$.

${ }^{106}$ The average of group 1 (Ex Ante Certain) $(\mathrm{M}=5.53, \mathrm{SD}=3.00)$; group 2 (Ex Post Certain) (M=4.81, $\mathrm{SD}=3.07)$; group 3 (Ex Post Probable) $(\mathrm{M}=4.59, \mathrm{SD}=3.08)$.

107 No significant interaction was found for the variable of judgment of compliance to fertilizer production, according to payment recipient (state, individual) and time and certainty of payment ( $\mathrm{p}>$.05). That is to say, the differences found between the averages of state and individual for willingness to comply were not related to time or certainty of payment.
} 


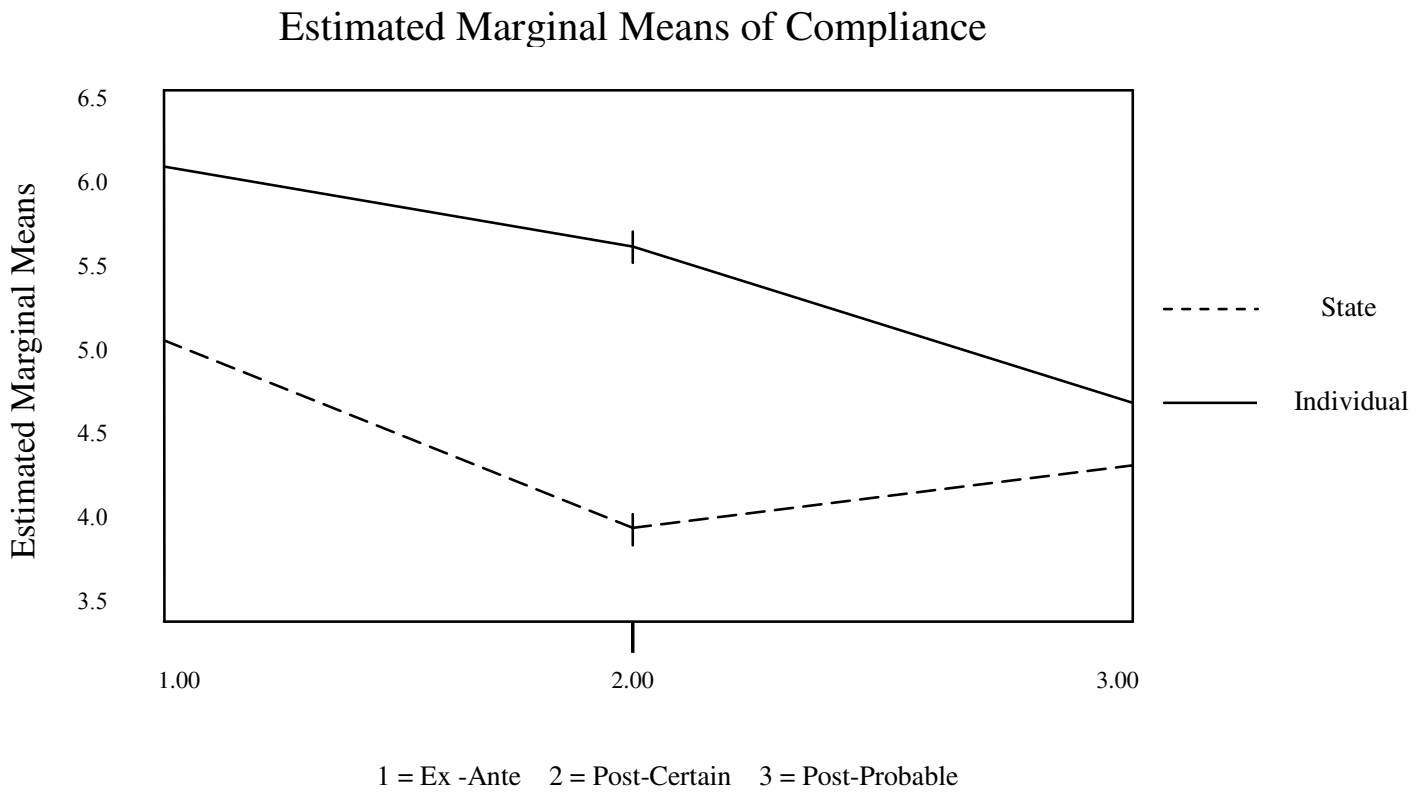

\section{6) Entitlement}

The sixth measure examined the differences between groups for the variable of demanding a high price for fertilizer production (ENTITLEMENT). ${ }^{108}$ This measure attempts to capture participants' overall dislike for engaging in the production in each legal setting. Hence, asking for a higher price represents their willingness to pay for not engaging in this practice. The ANOVA revealed no significant differences between the averages for the variable of payment recipient. However, the ANOVA did reveal a significant difference between the averages of the variable of time and certainty of payment, ${ }^{109}$ where the average of group 1 (Ex Ante Certain) was the lowest, after which came group 2 (Ex Post Certain), followed by group 3 (Ex Post Probable). ${ }^{110}$ The Post Hoc Tests revealed that the average group 1 was significantly lower than group 2 and 3, which were not significantly different from one another. In other words, demand for an especially high price in return for production was lower when the legal payment was made ex ante. 111

\footnotetext{
108 The range of scores for the variable of ENTITLEMENT ranged from $1=\mathrm{I}$ would refrain from asking for a high price for producing the fertilizer within the described legal situation, to $10=\mathrm{I}$ would ask for a high price for producing the fertilizer within the described legal situation. Table 1 displays the averages and standard deviations (in parentheses) of the variable of ENTITLEMENT, as a function of the payment recipient source and time and certainty of payment.

${ }^{109} \mathrm{~F}(2,380)=9.44, \mathrm{p}<.001, \eta 2=.05$.

${ }^{110}$ The average of group 1 (Ex Ante Certain) $(M=6.79, S D=2.31)$; group 2 (Ex Post Certain) $(M=7.42$, $\mathrm{SD}=2.06)$; group 3 (Ex Post Probable) $(\mathrm{M}=7.91, \mathrm{SD}=1.75)$.

${ }^{111}$ No significant interaction was found for the variable of ENTITLEMENT, according to payment recipient (state, individual) and time and certainty of payment ( $\mathrm{p}>.05)$. That is to say, the differences found between averages of state and individual for demand of an especially high payment for producing the fertilizer were not related to time or certainty of payment.
} 


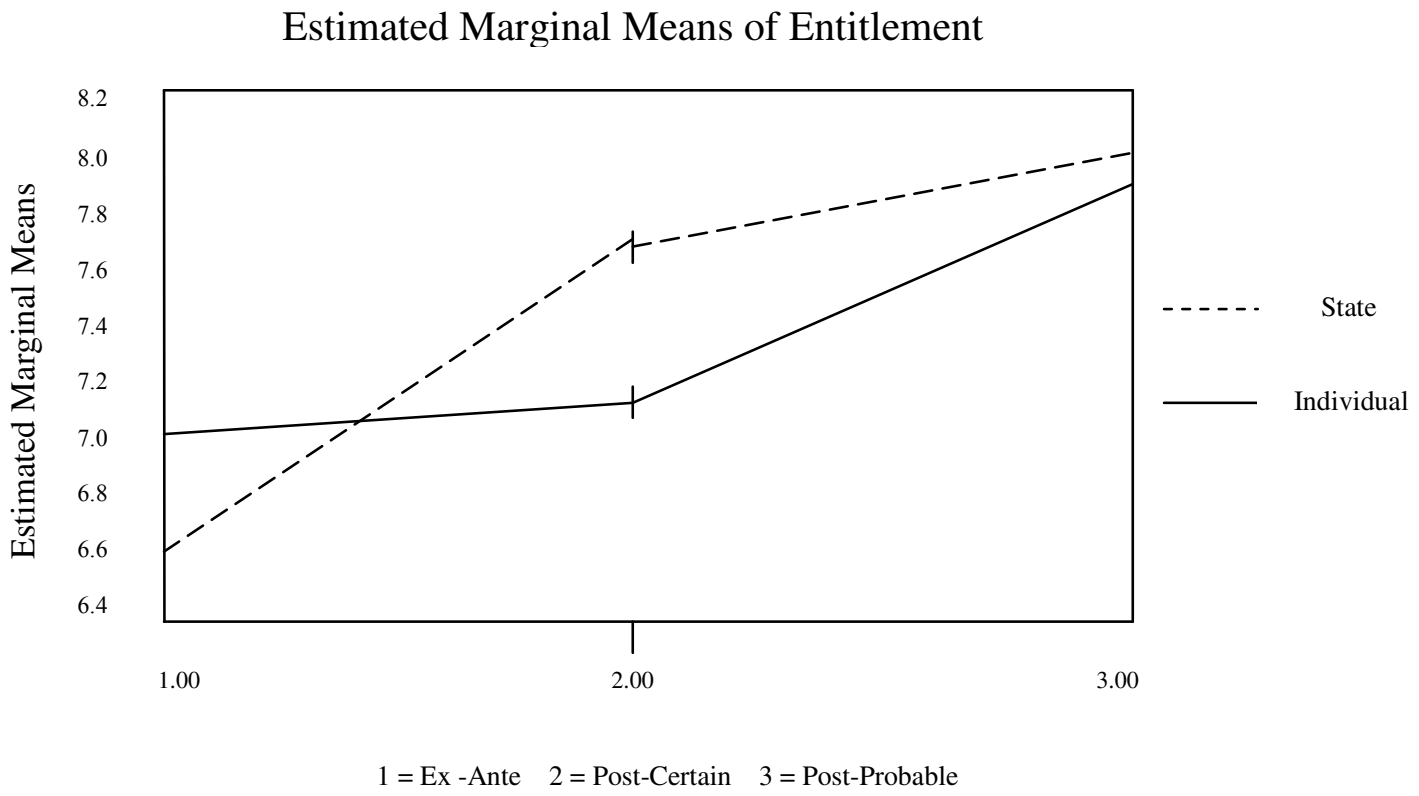

\section{B. Summary of the Results}

In contrast to rational choice predictions, we found that the structure of legal payments is of importance. The identity of the party receiving the payment, the timing in which it is made, and the certainty with which it is assessed, were all found to be related to most measured variables.

Identity of recipient - In all 6 measures, participants preferred a situation in which the payment was made to an individual rather than to the state. Overall, people thought this setting was more moral, and that production in it was more socially and legally acceptable. Perhaps most importantly, participants were more likely to produce the fertilizer in this situation. However, the difference was not significant regarding the price participants would ask for producing the fertilizer.

Timing of payment - A strong and significant difference existed between paying ex-ante and ex-post (both probable and certain). Participants thought it was more moral, and more socially and legally acceptable to produce the fertilizer when they made the payment ex-ante. Furthermore, participants were interested in a smaller profit for production in the ex ante condition compared with the ex-post condition. ${ }^{112}$

Certainty of payment - In all six measures, participants demonstrated a dislike for probabilistic payments. In five of the six measures it was significantly different from the ex-ante group, and not from the ex-post certain group. However, with regard to the measure of intention, participants differed significantly from the ex-post certain group, implying that when the payment was not certain they were less likely to produce the fertilizer when compared with the situation where the payment was certain.

\footnotetext{
112 The only exception was when the dependent variable was intention; in that case the ex-ante group differed significantly only from the third group of ex-post probable.
} 
Interaction between identity of the recipient and timing of the payment - A significant interaction emerged regarding the perception of legality. There was a difference between ex-post and ex-ante when the state was the recipient. However, when the individual was the recipient, there was no such difference. This pattern was also evident in some of the other measures (e.g. entitlement), but only with a marginally significant interaction. Thus, we found some evidence that the importance of the timing was stronger when the recipient was the state.

\section{DiscuSSION AND POLICY IMPLiCATIONS}

In this Section, we turn to explore the implications of our findings to legal policy making. First, we tie the findings of Section II to the theoretical literature reviewed in Section I. We then suggest several policy implications resulting from these findings. Due to the preliminary nature of this study, our suggestions in this regard will be tentative rather than definitive. Finally, we point out the limitations of our study, and outline future research that could help overcome some of these limitations.

\section{Are Fines Prices?}

In this article, we documented consistent and robust differences between legal payments due to their structure. This result runs against traditional economic theory that assumes that all legal payments are fungible. Thus, our findings suggest that the "fines are prices" paradigm should be revisited, and refined along the three dimensions we studied.

First, much like in other settings, people like certainty and dislike uncertainty with respect to legal payments. ${ }^{113}$ Our study demonstrated that people perceived probabilistic payments as less moral and less acceptable than certain payments. Furthermore, participants were less willing to engage in harm creating activity when a probabilistic element was added to equal legal payments. This result confirms our hypothesis and that of others writing on the deterrent effect of ambiguity. ${ }^{114}$ However, while this effect was consistent across all measures, it was not significant in all of them. The lack of significance across all measures might be explained by the fact that rational individuals are expected to strictly prefer the probabilistic option, given the fact that we held the size of the sanction constant. Thus, our finding in this measure could be interpreted as more powerful than might be suggested. Finally we note that our findings do not allow us to decipher what is driving them, since both cognitive biases associated with uncertainty aversion and the expressive meaning of probabilistic sanctions might be in place.

113 See Shawn P. Curley, J. Frank Yates \& Richard A. Abrams, Psychological Sources of Ambiguity Avoidance, 38 Organizational BeHAV. \& Hum. Decision Processes, 230 (1986). ,Hillel J. Einhorn \& Robin M. Hogarth, Ambiguity and Uncertainty in Probabilistic Inference, 92 PSYCH. REV. 433 (1985). Craig R. Fox \& Martin Weber, Ambiguity Aversion, Comparative Ignorance, and Decision Context, 88 ORG. BEHAV.\& HUM. DECISION PROCESSES. 476 (2002).

${ }^{114}$ Alon Harel \& Uzi Segal, Criminal Law and Behavioral Law and Economics: Observations on The Neglected Role Of Uncertainty In Deterring Crime 1 AM. L. \& ECON. REV. 276 (1999); Uzi Segal \& Alex Stein, Ambiguity Aversion and the Criminal Process, 81 NotRE DAME L. REV. 1495 (2006). 
Second, our findings demonstrate the significance of the timing of payment. In accordance with our predictions, paying before the harmful act rather than after it reduced the negative perception of the payment and increased the willingness of people to engage in harmful activity. This result follows the connection we drew between the paradigmatic structure of a price and the way in which legal payments are structured. In the private setting, ex ante payments could imply consent that was granted in return for the legal payment, thereby justifying the act. Ex post payments to individuals, on the other hand, do not imply consent, and therefore sustain the perception of the act being forbidden. In the context of the state, ex ante payments give saliency to the unique role of the state as a legitimate source of authority. Numerous studies of social psychology have documented the unique power of the state in securing obedience. ${ }^{115}$ This power was tested even in extreme cases such as torture. ${ }^{116}$ Thus, paying the state in advance and getting a license from it might be especially appealing for participants. Ex post payments to the state, however, employ the ability of state sanctions to shape people's moral reasoning and perception of wrongdoing. When such a payment is given to the state, it brings some greater moral appeal and social labeling against engaging in that behavior, increasing its impact above the cost of paying the sanction. ${ }^{117}$ This dimension of state based sanctions was confirmed in various empirical studies that focused on the moral effect of formal sanctions. ${ }^{118}$

Third, in accordance with our predictions, people were more willing to engage in harmful behavior when the individual harmed by the act, rather than a third party, received the payment. This result suggests that the framing of a payment as compensation implies a different social meaning. Compensation brings the parties closer to the paradigmatic price, especially in cases where the losses suffered by the injured party are purely monetary. It removes (to a certain degree) the harm caused to the injured party from the decision making calculus, thus allowing individuals to consider their personal benefit.

Finally, the interaction between the identity of recipient and the time and certainty of payment provides additional support for the fine is a price paradigm. ${ }^{119} \mathrm{~A}$ post hoc analysis that followed the interaction demonstrated that when the state was the recipient, the timing had a greater effect on the attitudes of the participants in comparison to when the recipient of the payment was the individual. Since many

\footnotetext{
${ }^{115}$ Herbert C. Kelman \& Lee Hamilton, CRIMES OF OBEDIENCE: TOWARD A SOCIAL PSYCHOLOGY OF AUTHORITY AND RESPONSIBILITY (1989).

116 See, Herbert C. Kelman, The Social ConteXt of Torture: Policy Process AND Authority STRUCTURE (1995) (discussing the sources of the power of the state to give people (in our terminology) a moral license to harm others).

${ }^{117}$ See Dan M. Kahan, Social Influence, Social Meaning, and Deterrence, 83 VA. L. REV. 349, 352-361 (1997).

${ }^{118}$ Frank Zimring \& Gordon Hawkins, The Legal Threat as an Instrument of Social Change, 27 J. SoC. ISSUES 33 (1971) (examining how punishment traditionally associated with price might teach right and wrong.); Kirk R Williams \& Richard Hawkings, Perceptual Research on General Deterrence: A Critical Review, 20 L. \& SoC. REV 545 (1986) (distinguishing between mere deterrence (formal cost), normative validation (internalization) and social deterrence (social cost)); Raymond Paternoster \& Sally Simpson, Sanction Threats and Appeals to Morality: Testing a Rational Choice Model of Corporate Crime, 30 L. \& SoC. REV. 549 (1996) (showing that the greater is the sanction, the greater is the moral wrongdoing associated with the sanctioned behavior).

${ }^{119}$ The interaction between the identity of the recipient and the timing of the payment was significant only in one measure, it was evident, albeit in weaker forms, in some of the other measures, as well.
} 
paradigmatic prices are paid in advance (e.g., the classic spot market transaction), while fines are usually paid after the fact, it was expected that people would be more willing to engage in production when the payment was done in advance. However, because it is easier to view the payment as a fine when the state is the recipient of the payment, the effect of timing is likely to have a stronger effect in those scenarios than when the individual is the recipient. Furthermore, when the state is the recipient of the payment, shifting it ex ante is of greater significance, since it transforms the situation in to one in which the individual acts in complete compliance with the law. Hence, the timing of the payment should receive greater attention by policymakers when the recipient of the payment is the state.

To sum up, there appears to be a continuum of legal payments that are perceived differently by people, and as a result generate distinct incentives. At one end of this continuum lie legal payments that are similar in structure to a paradigmatic price. These are payments made to another private party in advance. At the other end of the continuum lie legal payments that are similar in structure to the paradigmatic punishment. These are payments that are made after the fact to the state, and that their assessment is probabilistic. As legal payments shift from the price side of the continuum to the punishment side of it, people begin to see the payment triggering activity as less moral, and as a result they are less willing to engage in it.

\section{Choosing Between Alternative Legal Regimes}

So law does matter. Legal payments are not mere prices, and the choice between them may affect the way in which people behave. That given, we turn to review some of the implications of our findings for the design of optimal legal rules. At the outset we would like to emphasize that due to the preliminary nature of our project, our suggestions should not be read as definitive calls for swift legal reform. Rather, we attempt to point out several policy debates that should be revisited both theoretically and empirically in light of our findings.

The general implication of our work is that when policymakers choose between legal regimes they not only set monetary consequences for different types of behavior, but also determine how people will perceive those consequences. While some legal payments are perceived as prices and therefore encourage people to conduct cost benefit analyses, others exclude such considerations from peoples' decisions. Thus, the choice between different modes of payment should focus on whether policymakers want to encourage non-compliance in cases in which the benefit people derive from the activity is larger than the legal payment. If policymakers aim to promote efficiency, and can set legal payments such that they capture the full social harm caused by the harmful activity, there is a clear advantage in framing legal payments as prices. In these cases, our analysis would support exante payments made to the parties harmed by the act. These payments would help crowd out people's intrinsic motivation not to harm others, and cause them to engage in the harm-generating behavior, as long as it is beneficial for them to do so. If, on the other hand, policymakers aim to reduce harmful activity notwithstanding its efficiency, they should consider framing the payment as far away from prices as possible, making the payment probabilistic, succeeding the harmful activity, and without reference to compensation. Such framing could create additional deterrence without increasing the size of the payment. This could be especially useful when 
political forces limit the ability to raise sanctions or when harm doers have limited resources.

Pollution is a classic example of a harmful activity that we want people to engage in if the benefits arising from it outweigh its harms. ${ }^{120}$ Policymakers tend to recognize that command and control regulation might create inefficiencies that environmental taxes can prevent. $^{121}$ Our findings confirm this assertion, and demonstrate that pollution taxes could encourage people to conduct cost benefit analyses. ${ }^{122}$ Furthermore, our results could inform the optimal design of pollution taxes in a way that will increase the chance that people view it as a price. For example, making sure that people realize that the tax compensates the individuals harmed by pollution will increase the chance that they view it as a price. Indeed, several scholars have attacked some of the underlying rationales of pollution taxes, suggesting that emission taxes be used to compensate those who are harmed by pollution, ${ }^{123}$ yet they have focused on the distributive arguments rather than on behavioral analysis. Similarly, the certainty of detection is also important to prevent an association with fines. Employing new technological tools that will assure complete detection will cause polluters to perceive the taxes they pay as mere prices.

The results offer an additional perspective to the current debate regarding the behavioral effects of environmental regulation. Some have argued that the effect of taxation on behavior is contingent upon the size of the tax. ${ }^{124}$ Large and small taxes would reduce pollution while intermediate taxation would crowd out intrinsic motivation, while not suggesting a costly enough incentive to abstain from polluting. In that regard, Frey calls for the use of other means of regulation with a more limited crowding out effect. Others have argued that the predictions of Frey are uninformative since they fail to account for numerous factors related to the framing of the payments (e.g., tax versus subsidy, etc.). ${ }^{125}$ Based on the findings accumulated in this paper, it is safe to say that the perspective taken by Frey is indeed unsatisfactory, as it focuses on the size of the payment as the sole factor which would moderate the level of crowding

\footnotetext{
${ }^{120}$ We do not wish to defend the strong utilitarian claim that any harm to the environment that creates greater benefit is justified. All we claim is that some type of cost benefit analysis in the environmental context is essential. For a discussion see CASS R. SunSTEIN, FREE MARKET AND SociAL JUSTICE 193 (1997).

${ }^{121}$ Mikael S. Andersen, Governance by Green Taxes. Making Pollution Prevention Pay (1992). See also, Britt Groosman, Pollution Tax (2500) p. 538 in, ENCYCLOPEDIA OF LAW AND ECONOMICS, VOLUME II. CIVIL LAW AND ECONOMICS (Boudewijn Bouckaert \& Gerrit De Geest eds., 2000). For econometric evidence on its impact see Robert W. Hahn, The Impact of Economics, 39 ENVTL. POL'Y J. ENVTL. ECO. \& MGMT. 375 (2000); Robert N. Stavins, Experience with Market-Based Environmental, Policy Instruments, (working paper, Kenedy School of Government) (2001).

${ }^{122}$ For a support of this argument that environmental taxation would crowd out internal social norms of environmental protection by polluting factories, see Lai Ching-Chong, Yang Jen Chih \& Yu Juin Chang, Environmental Regulations and Social Norms, 10 InTERNATIONAL TAX \& PUBLIC FinANCE 63 (2003)

${ }^{123}$ See Britt, supra note 121 for a discussion of the scholarly debate on the justifiableness of using pollution taxes.

${ }^{124}$ Bruno S. Frey \& Alois Stutzer, Environmental Morale and Motivation, Working paper no. 288 Institute for Empirical Research in Economics University of Zurich (2006).

${ }_{125}$ Karine Nyborg, Informational Aspect of Environment Policy Deserves more Attention, $22 \mathrm{~J}$. CONSUMER POL'Y 419-427 (1999).
} 
out. Frey's model ignores the importance of factors such as certainty, timing and identity of who receives the money. In a real-life context, there is a limit to the magnitude of payment a state can request from individuals and hence the importance of how the payment is framed could be an effective policy tool. ${ }^{126}$

Turning to the issue of uncertainty, the findings reported in this study imply a conclusion that runs against the conventional wisdom of enforcement. The comparison between the probabilistic groups and the certain groups showed that raising the probability of detection to $100 \%$ while holding the size of the sanction constant could cause more people to behave in a harmful manner. Thus, contrary to the prediction of rational choice theory, that any increase in the probability of detection will also increase deterrence, our results suggest that the unique shift to certain payments might actually reduce deterrence because it will change the social meaning of the sanction. Take for instance the issue of the enforcement of traffic laws. Current technology allows regulators to detect some violations of these laws with complete certainty using a combination of "black boxes" and GPS. ${ }^{127}$ Rental companies have already used this technology in order to fine customers who drove their cars above the speed limit. ${ }^{128}$ While traditional analysis would suggest that utilizing such technology will necessarily increase compliance (or allow for a reduction of the level of sanctions), our analysis suggests that shifting to a regime in which sanctions are $100 \%$ certain might cause people to be more willing to engage in cost-benefit analysis, bringing about lower compliance. ${ }^{129}$ Consequently, in such situations, there is a need to increase the magnitude of the payment in order to sustain a given level of deterrence.

\section{Limitations of the Current Study and Suggestions for Further Refinements}

In this final subsection, we evaluate the potential criticisms to this project. We outline the limitations of our results, and along the way sketch out additional research that can help deal with these limitations, thus deepening our understanding of legal payments.

The first limitation of the results is the high standard deviation measured for participants' price request estimations (asked in return for their agreement to produce the fertilizer), and therefore this measure did not yield significant differences between the sub-groups of the sample. This large variation in people's responses might be

\footnotetext{
126 For example, Shavell describes the limits of the legal system to deter companies from taking risks which exceeds their assets. Given that these companies cannot pay for the losses they might cause, they become in Shavell's terminology 'Judgment-Proof'. In such situation, the importance of the dimensions we explored in this paper become even more important, since they would make it possible to create high enough deterrence, in cases, where other factors might prevent a net increase in the magnitude of the fine. See Shavell, supra note 8 at 230-31.

${ }_{127}$ Aaron Renenger, Satellite Tracking and the Right to Privacy, 53 HASTINGS L.J. 549, 553-4 (2002).

128 Id.

129 This will depend on how people perceive the probability of detection prior to the use of the new technology. If it was perceived to be low then the increase in the probability of detection can outweigh the certainty effect. In this regard our results suggest that more compliance can be achieved by raising the probability of detection to a level that is bellow the $100 \%$ threshold, which will allow policymakers to preserve the deterrence power of uncertainty.
} 
related to the difficulties people faced when they attempted to make an estimation of a price with such limited information. Future research could try to deal with this problem by giving participants more detailed information about the circumstances of the case. Such additional information could improve the ability of participants to give more accurate estimates of the price they would be willing to pay in such circumstances. ${ }^{130}$

A second limitation might be seen in the strong feelings of social desirability that may have been evoked by the selected experimental scenario. Indeed, participants in our study were requested to admit what amounts to their willingness to profit at the expense of others. This fact might have a greater effect on answers regarding the identity of the recipient, since in that case people might feel that it would look better if they are willing to produce the fertilizer only when they compensate the damaged party. With regard to the timing of the payment and the probability of detection, the social desirability effect might still exist, but is expected to be weaker, as choices are more equal in their perceived desirability.

A third limitation of our study might stem from the way in which we chose to describe the harm caused. Our experimental setting was a unique case where a clear victim existed, both when the payment was made to the state and when the payment was made to the individual. In many real world cases, however, there is no identifiable victim, and one can only identify a group of people of whom only some were harmed by the act (e.g., the factory causing a probabilistic harm to a neighboring village). In these contexts, locating an individual victim and making a direct payment to her, might work in the reverse direction, making people more resistant to view the payment as satisfactory. Along those lines, our findings should not be generalized to situations in which the harm cannot be quantified or fully compensated. ${ }^{131}$ For instance, in most bodily harm cases, it is extremely complicated to measure the harm precisely and to fully compensate for it. Furthermore, even when only property damage is at stake, many real settings involve numerous victims with a large variety of damages. In such cases, the move from fines to prices is expected to be more complicated. While, as we argue above, in such cases we might want to prevent a transformation from fines to prices, it is essential to explore experimentally the perception of people in such settings, and examine whether the pattern we presented in this study is replicated.

A fourth limitation comes as a result of the fact that participants were asked to make a business-like decision in which one business entity harms another. One should be careful not to generalize from the selected business-like setting to all types of disputes, since our setting may have signaled to participants a need to employ a calculative approach, rather than a moral or emotional one. Arguably, in more private settings (e.g., a neighbor dispute), people might tend to employ such perspectives when evaluating legal payments. For instance, Baker documented substantial differences between the way tort victims treat money they receive from liability

\footnotetext{
${ }^{130}$ Nonetheless, as explained earlier, we measured on a Likert scale participants' estimation of the magnitude of the sum they would request [entitlement], this measure was intended to captures the same behavioral estimate.

131 For a review of the incommensurability literature and its implications to our study see supra notes 59-62.
} 
insurance companies and money they receive directly from tortfeasors. ${ }^{132}$ With respect to the first, victims clearly aim to maximize the amount of payments they receive. ${ }^{133}$ With respect to the second, however, social norms labeling this money as "blood money" limit (actually, almost eliminate) its value, causing victims not to pursue compensation from "real people." ${ }^{\text {.134 }}$ Hence, future research should examine whether changing the setting impacts the pattern, which was evident in this case.

A fifth limitation was caused by the fact that all payments made to a third party in our study were made to the state. However, payments to the state create two effects, which are hard to separate in a single comparison: (a) the victim is not being compensated, and (b) the expressive power of the state is at work. Situations in which the third party collecting the payment is not the state (e.g. a trade association) might bring about different results. For example, Baker documented differences between the way people treat money paid to insurance companies and money paid to victims of tortuous acts. ${ }^{135}$ In that sense, paying an insurance company creates an ideal intermediate category, where the individual is not getting paid on one hand, and the state's expressive power is not being triggered on the other. Future research should test all three scenarios on one subject, allowing for greater isolation of each of the effects that are unique to the individual and the state.

Additionally, our questionnaire did not attempt to control for the size of the payment. Much of the crowding out literature has argued that the magnitude of this effect could depend on the size of the monetary incentives being used. Frey, for example, has argued that there is a U-shaped connection between the size of the incentive and the crowding out of intrinsic motivation, such that crowding out is strongest with intermediate payments. ${ }^{136}$ Thus, controlling for the size of the payment is expected to interact with the tendency of people to view the payment as a price, and their willingness to engage in harm-generating behavior.

Finally, one should recognize the general limitations of the methodology we employed. Measured items were basically attitude scales. Given the extensive literature on the complexity of the attitude-behavior relationship, ${ }^{137}$ one ought to be careful not to over-state these findings. Future research should attempt to combine other methodological approaches with additional types for proxies of behavior. ${ }^{138}$ That said, it should also be recognized that numerous studies have documented the validity of using intention as a proxy for behavior. ${ }^{139}$ Thus, we expect that the current pattern of findings should be replicated using other methodologies.

A separate set of questions that we leave for future research relates to how the legal framing of payments affects the behavior of the recipients. Our study was motivated by the view of legal payments as prices, and therefore focused exclusively

${ }^{132}$ See Tom Baker, Blood Money, New Money, and the Moral Economy of Tort Law in Action, 35 L. \& SOC. REV. 275 (2001).

${ }^{133}$ Id at $281-301$.

${ }^{134} \mathrm{Id}$.

135 Id. at 301-13 (discussing the concept of 'new money').

${ }^{136}$ See Uri Gneezy \& Aldo Rustichini, Pay Enough or Don't Pay at All, 115 Q. J. Econ. 791(2000).

137 See Yuval Feldman, Attitudes and Behavior, in ENCYCLOPEDIA OF LAW AND SOCIETY AMERICAN AND GLOBAL PERSPECTIVES (forthcoming 2007).

${ }_{138}$ As in game based settings.

${ }^{139}$ Ajzen, supra note 102. 
on the paying side of the legal equation. However, distinct legal payments could have different meaning for the receiving side as well. For example, aiding the poor through the tax system or through private law could create different motivations on the side of the receiving party, even if they receive identical sums of money. The traditional economic approach to the question of which type of redistributive tool is superior is that the tax and transfer system is the most efficient way to redistribute wealth since income taxes only create inefficiencies associated with distorted work incentives while redistributive private law rules create the same distortions regarding work, and additional distortions with respect to the activity that they regulate. ${ }^{140}$ Recently, Lewinsohn-Zamir has argued that once the fungibility assumption is relaxed and we acknowledge that there could be differences between dollars received from the tax and transfer system and those received through private law, the use of private law in order to redistribute wealth could be justified from a consequentialist perspective. ${ }^{141}$ Nonetheless, this theoretical conclusion was based on behavioral studies that did not explore the unique nuances of legal payments. A complete theory of efficient redistribution should follow along the lines we set in this study, and explore the differences between different types of redistributive legal payments.

Our results also suggest an array of potential studies in the area of optimal contract design. For instance, our findings offer an additional perspective on the choice made by contracting parties between liquidating damages in the contract and relying on courts to determine them after the breach has occurred. While we do not disagree with the existing literature outlining the different considerations relevant to this choice, ${ }^{142}$ we find it incomplete in the sense that it treats liquidated damages and court determined damages as fungible. Our analysis suggests, however, that liquidated damages might be perceived differently by the potential breaching party. The fact that liquidated damages are set ex ante might cause potential breachers to view them as a payment that is closer to a price. ${ }^{143}$ Thus, all things being equal, contracting parties are expected to be more willing to breach and pay damages when damages are set prior to the breach.

Given the price nexus between contracting parties, a contract design that promotes additional breaches is desirable from their perspective since it could help promote efficient breaches during the performance of the contract. As long as damages are liquidated such that they reflect the full cost of breach, all breaches enlarge the size of the contractual pie. Case in point, the fine imposed in the day care center that Gneezy and Rustichini studied. Arguably, in such a setting one can easily calculate the harm caused by parents coming in late, which mostly consists of the

\footnotetext{
140 See, e.g., Louis Kaplow \& Steven Shavell, Why the Legal System Is Less Efficient Than the Income Tax in Redistributing Income, 23 J. Legal Stud. 667 (1994).

${ }^{141}$ Daphna Lewinsohn-Zamir, In Defense of Redistribution Through Private Law, 91 MINN. L. REV. 326, 362-72 (2006).

${ }^{142}$ See, e.g., Charles Goetz \& Robert Scott, Liquidated Damages Penalties and the Just Compensation Principle: Some Notes on an Enforcement Model of Efficient Breach, 77 COLUM. L. REV. 554 (1977); Philippe Aghion \& Benjamin Hermalim, Legal Restrictions on Private Contracts Can Enhance Efficiency, 6 J. L. ECON. \& ORG. 381 (1990); Alan Schwartz, The Myth that Promises Prefer Supracompensatory Damages: An Analysis, 100 YALE L.J. 369 (1990).

${ }^{143}$ To be sure, the case of liquidated damages is distinct from our experimental setting in the sense that both liquidate damages and court determined damages are paid after the breach. Hence, one should view the liquidated damages situation as a unique hybrid case in which the payment is assessed ex ante but actually made ex post.
} 
value of the time of the employees who are required to stay in late. The introduction of the fine could assist the day care center and the parents in reaching an efficient outcome by capturing the surplus between the value of the time of late parents and the value of the time of the day care center's employees.

\section{CONCLUSION}

We began this study with a question: are all 'legal dollars' created equal? And we end it with an answer: no, they are not. We identified three structural characteristics of legal payments that create consistent differences between them: the identity of the party receiving the payment, the timing in which it is made, and the certainty in which it is assessed. The shift between the different payments gradually transforms prices into punishments, and changes the way people treat legal payments. This result runs against the fundamental assumption of economic analysis of law that all legal payments are fungible. We then demonstrated that relaxing this assumption suggests that an array of policy debates ranging from environmental regulation to law enforcement should be revisited in order to fully understand the effects of legal regimes that seem to be equivalent from an economic perspective.

While the results we present are robust, in the sense that they demonstrate differences between legal payments, one should note that this study has explored a point not studied before, and that there is much more work to be done before we fully understand the differences we documented. Thus, we cannot offer at this point a comprehensive theory explaining the differences between all legal payments in every conceivable context. In order to progress towards development of such a theory, we offered several suggestions for future research that could help broaden our understanding of the distinctions between legal payments. Undoubtedly, deciphering the social meaning of legal dollars is a tricky task. If one intends to utilize law in an optimal fashion, it is an essential task as well. 


\title{
APPENDIX A - METHODOLOGY
}

\author{
QUESTIONNAIRE
}

\section{Attitude Survey}

The following survey is designed to test your attitudes regarding legislation on dumping chemicals into Israeli lakes.

\section{Generic Scenario:}

Assume that you own a fertilizer factory located adjacent to a small lake. You recently received an order for fertilizer, which the factory has not previously produced. It will cost the factory 200,000 Shekels [around $\$ 50,000$ ] to produce the order. Producing this particular fertilizer also involves dumping a new kind of chemical into the lake. The only effect of dumping this chemical into the lake will be to raise the production expenses of a neighboring fertilizer factory, which is also located at the edge of the same lake. With the exception of the neighboring factory, the lake water is not used by anyone else. Additionally, the new chemical does not cause any medical problems or damage to the environment.

Manipulation A: ex-ante-state

By law, before dumping the new chemical into the lake, you must pay a license fee of 100,000 Shekels (around \$25,000). You cannot purchase the raw materials needed to make the new chemical without presenting the permit attained by paying this fee. With the exception of paying this fee, you do not anticipate any other expenses.

\section{Manipulation B: ex-ante-individual}

By law, before dumping the new chemical into the lake, you must pay the neighboring factory a sum of 100,000 Shekels (around $\$ 25,000$ ). You will be able to purchase the raw materials needed to make the new chemical only after presenting a permit showing that the neighboring factory received the aforementioned payment. With the exception of paying this fee, you do not anticipate any other expenses.

\section{Manipulation C: ex-post-individual-certain}

By law, after dumping the new chemical into the lake, the neighboring factory can sue you for the resultant increase in his production expenses. There is no question that the neighboring factory will notice that you dumped the chemical, take you to court, and win the lawsuit. The anticipated cost of the lawsuit is 100,000 Shekels (around $\$ 25,000)$. With the exception of paying this fee, you do not anticipate any other expenses.

\section{Manipulation D: ex-post-individual-probabilistic}

By law, after dumping the new chemical into the lake, the neighboring factory can sue you for the resultant increase in its production expenses. If the neighboring factory 
notices that you have dumped this new chemical into the lake, and if it sues you, the anticipated cost of the lawsuit is 100,000 Shekels (around \$25,000). That said, the possibility exists that the neighboring factory will not notice that you have dumped the chemical, and you will therefore not have to pay anything. With the exception of the possibility of paying this fee, you do not anticipate any other expenses.

\section{Manipulation E: ex-post-state-certain}

By law, anyone who dumps a new chemical into the lake will be fined 100,000 Shekels (around $\$ 25,000$ ) by the municipal authority. On account of state-of-the-art chemical detection equipment installed next to your factory, there is no question that the spillage will be detected (after the fertilizer production order has already been completed). With the exception of the possibility of paying this fine, you do not anticipate any other expenses.

\section{Manipulation F: ex-post-state-probabilistic}

By law, anyone who is caught dumping a new chemical into the lake will be fined 100,000 Shekels (around $\$ 25,000$ ) by the municipal authority. That said, there is a certain chance that you will not get caught, as the authorities may not detect any spillage. No matter what, there is no doubt that you will manage to complete the fertilizer production order before the authorities will be able to detect the spillage. With the exception of the possibility of paying this fine, you do not anticipate any other expenses.

\section{Control:}

The control group did not undergo any manipulation.

Questions (for all groups):

1. What is the minimal price you will request for producing the fertilizer, within the framework of the legal situation described above (reminder: production costs total 200,000 Shekels)?

2. Producing the fertilizer within the framework of the legal situation described above is ethically objectionable: 1 (not objectionable) - 10 (objectionable).

3. Producing the fertilizer within the framework of the legal situation described above is an appropriate step for me, personally: 1 (inappropriate) -10 (appropriate).

4. Producing the fertilizer within the framework of the legal situation described above does not contradict the law: 1 (contradict) - 10 (doesn't contradict).

5. As much as possible, I will try not to produce the fertilizer within the framework of the described legal situation: 1 (will not try) - 10 (will try).

6. Within the framework of the described legal situation, for the production of the fertilizer, I will ask for an especially high price.1 (low price) - 10 (high price). 